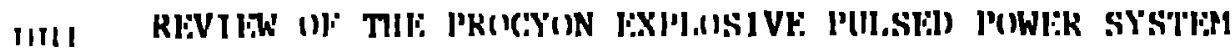

\begin{tabular}{|c|c|c|c|}
\hline & & & 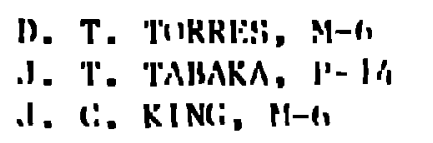 \\
\hline 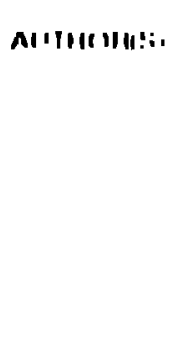 & 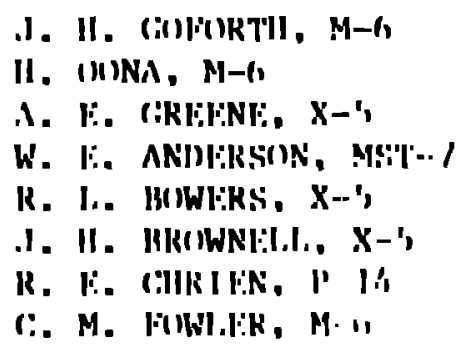 & 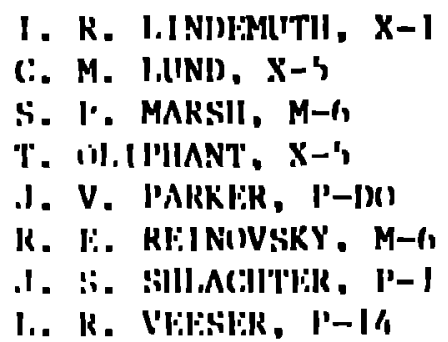 & 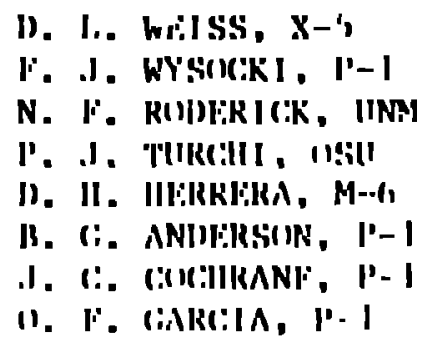 \\
\hline
\end{tabular}

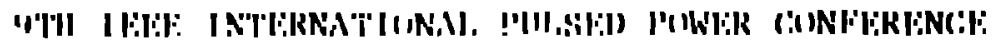

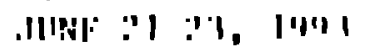

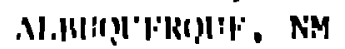

\title{
DIST I.AIMBR
}

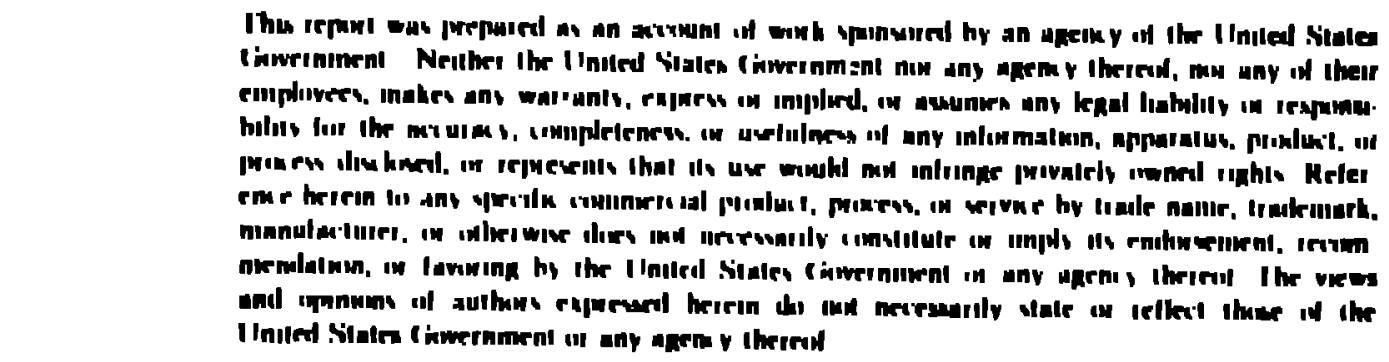

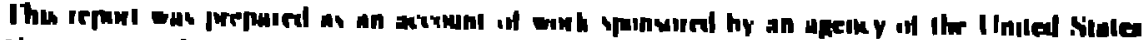

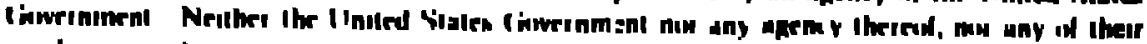

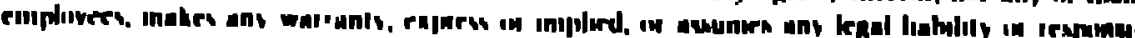

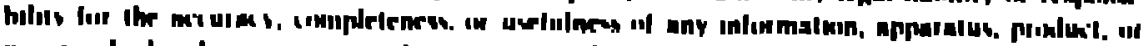

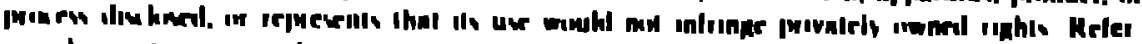

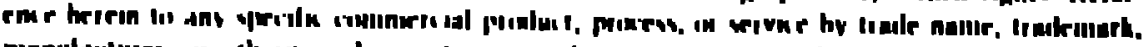

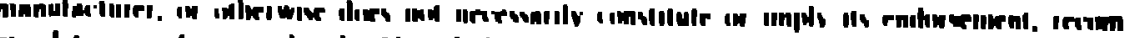

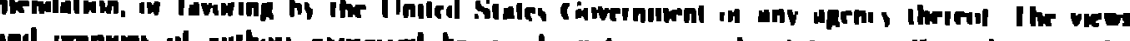

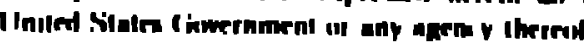


REVIEW OF THE PROCYON EXPLOSIVE PULSED POWER SYSTEM

J. It. Goforth, H. Oona, A. E. Greene, D. H. Herrera, D. L. Peterson, B. G. Anderson, W. E. Anderson, J. H. Brownell, R. L. Bowers, R. E. Chrien, J. C. Cochrane, C. E. Findley, M. F. Fowler, O. li. Garcia, M. L. Hodgdon, J. C. King, 1. R. Lindemuth, C. M. Lund, S. P. Marsh, T. Oliphent, J. V. Parker, R. I:. Reinovsky, J. S. Shlachter, L. J. 'labaka, D. IT. Torres, I.. R. Veeser, D. I. Weiss and IF. J. Wysocki, I.ANL

N. li. Roderick, UNM

P. J. 'Turchi, (OIIO) STA'ATi UNIVI:RSI'T Y

13. J Warthen, licikeci

\section{ABS"IRAC"I}

'The Procyon explosive pulsed power system is designed fior powering plasmil z-pincli experiments It hegins with a helicul explosive-driven magnetic llux compression gentenalon

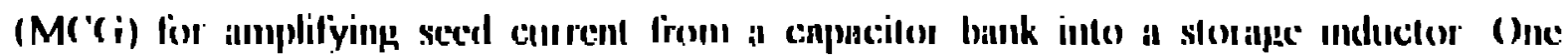

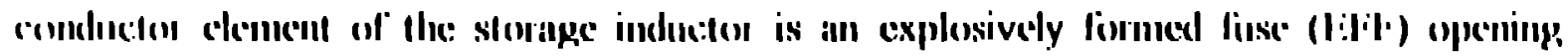

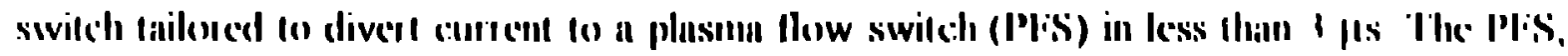

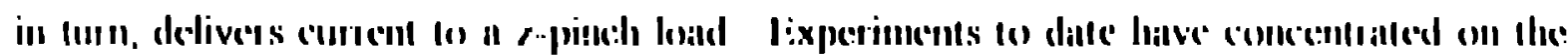

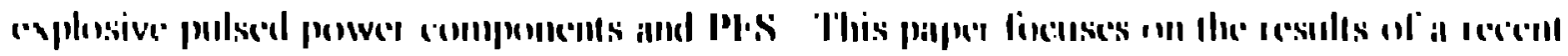

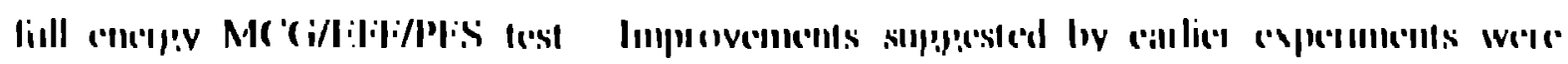

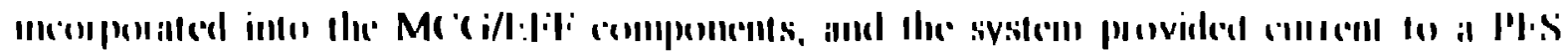

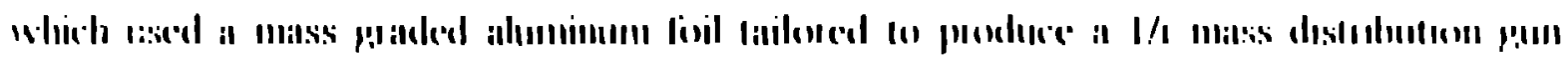


plasma. The $1 / r$ mass distribution is a departure from the standard practice of using a distribution of $1 / r^{2}$, and was included as an attempt to generate a different opening posture for the PliS. In addition, improvements in foil deposition technique allowed us to use a graded foil in place of the previously used cordal wire arrays. In the test, $21.4 \mathrm{MA}$ was generated in a $79 \mathrm{nll}$ storage inductor providing over $18 \mathrm{MJ}$ of magnetically stored energy. 'The liFF then diverted 16.4 MA to the PIS with a 10-90\% pulse rise time of $1.0 \mu \mathrm{s}$. System improvements led to currents aboul 7\% larger than in previous tests, and faster perliormance of the fiff. As a result, the PISS received a higher and faster current pulse than that used : preshot computations, and the overall performance was better than expected is mucli as 15.5 MA was delivered to the 4-cm-radius load slot with a $10-0(1) \%$ rise line of 300 ns. We now have a pulsed power supply that is able to drive I MJ implosions, and has the potential to scale beyond 2 MJ with optimized perfomance. fior loids that can operate with lower inductance feeds and that achicve higher meteases in indelactance. load energiess approaching $5 \mathrm{MJ}$ are possible.

\section{INITR()I)IIC"IIIN}

In this palper, we will deserribe the Procyon system and its perlonmance We will also comment on the amount of increased perfornatace to be obtained either by optimizing the

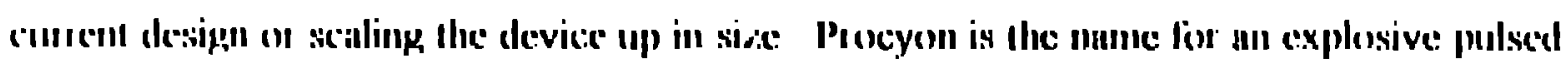

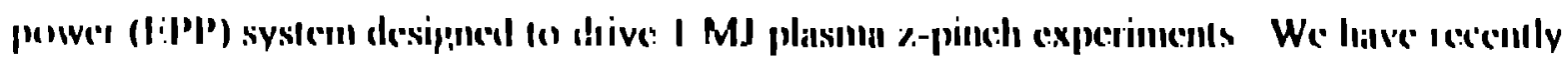

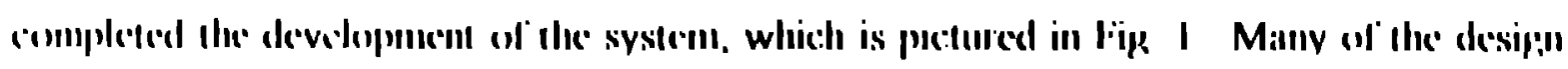

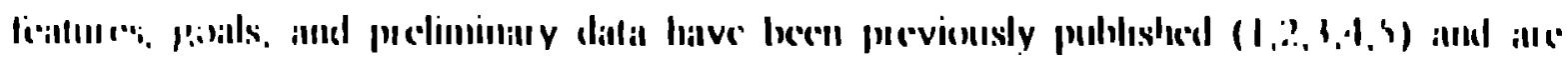

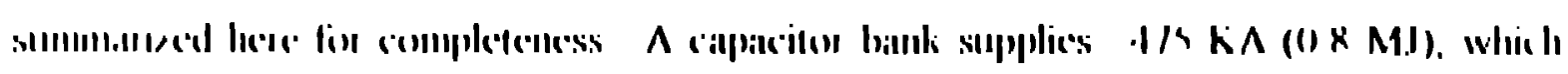

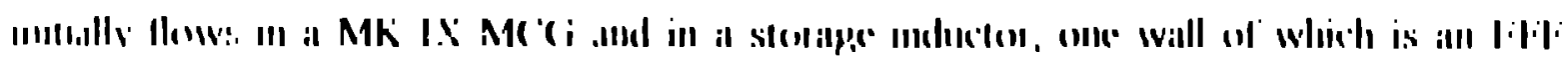

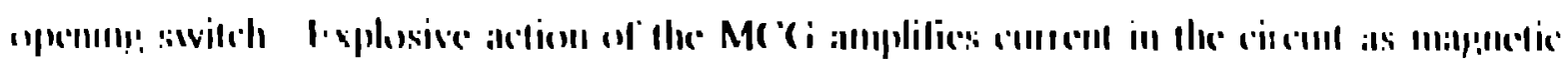

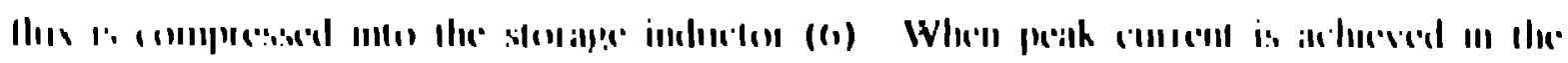


storage inductor, the EFF is actuated producing resistance in the switch. The voltage across the switch also appears across closing switch plates, and the closing switches are actuated when the desired voltage is achieved. The opening of the EFF diverts current to a PFS (7) that isolates the implosion load from the $2-3 \mu$ s EFF pulse, then commutes current to the load at or near peak PFS current. The initial storage inductor current is divided inductively as flux fills each successive volume. In our most recent test, our storage inductor was $79 \mathrm{nH}$, and the power flow system associated with the PFS was $23 \mathrm{nll}$. 'The PFS gun was $5 \mathrm{nH}$ and switched into a $2.6 \mathrm{nH}$ dummy load slot. On the test, we developed $21.4 \mathrm{MA}$ in the storage inductor (18.1 MJ) and diverted 10.4 MA to the PFS with a $10-90 \%$ rise time of $1.6 \mu \mathrm{s}$. $\Lambda \mathrm{l}$ this time, $13.9 \mathrm{MJ}$ remain in $103 \mathrm{nl}$. The Plis for the test was designed to open in a gating action because the PliS plasma mass density varied as $1 / r$ in the bartel where forces vary as $1 / r^{2}$. T'ic current pulse was larger and faster than expected, and as a result, the PISS "gated" open while only $2-3 \mathrm{~cm}$ down the $7 \mathrm{~cm}$ barrel. The downstream switching results are exciling, and will be described here and in another paper in the conference (8) At a probe position inside the load slot and near the upstream electrode, $15.5 \mathrm{MA}$ was developed with a 10 - $90 \%$ rise time of 500$)$ ns Prohes in the

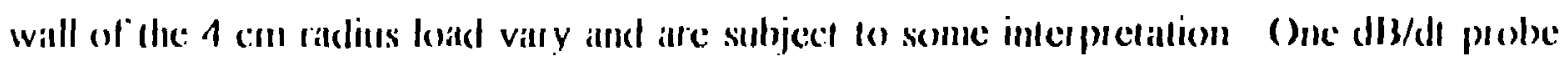

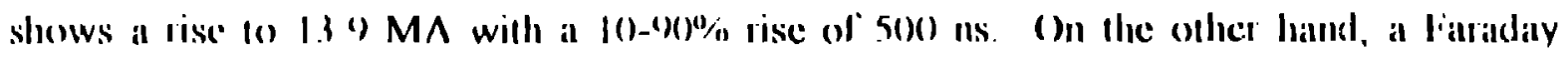
rotation signal shows that as much as 15.5 MA was switched with a 10 . . 90"..n risetime of

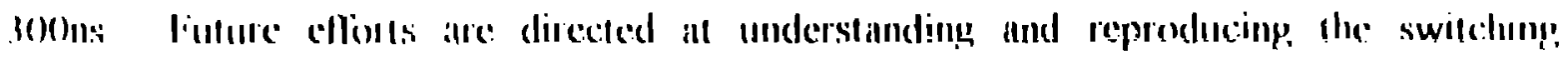
(b) served

APIRRATIS

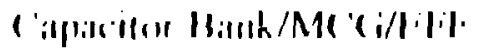


A Procyon circuit diagram is given in Fig. 2 and a cross section of the liPP and load sections in Fig. 3. The initial energy for a Procyon test is supplied by two $3000 \mu \mathrm{F}$ capacitor bank modules charged to $\sim 18 \mathrm{KV}$. 'To shorten the energy delivery time, we connect the modules in series, effectively creating a $1500 \mu \mathrm{li}, 36 \mathrm{KV}$ bank. We described our two stage Marx system header earlier (9). Marx header failures during Procyon tests, however, led us to redesign the system to provide a high degree of control on the cleanliness and atmosphere around the header. Operating procedures now require the system to be flushed with dry nitrogen, then filled with $\mathrm{Sl}_{6}$, at atmospheric pressure and ambient temperature. 'The capacitor bank is discharged through the header into the IilP' system dominnted by the 7.2 HLI MK-IX generator. Contributing to header tailures were voltage reflections generaled at the input to the $7.2 \mu \mathrm{H}$ inductance. In lests with simulated MC' (i's, reflections were recorded at the Marx header that were nearly denble the voltage of' the two modules To alleviate this rellection, we installed a $4 \$ 2$ resistor array at the input 10 the MK-IX. With these resistors in the circuit, the ringing of the heater voltage is rediced as shown in lïg. 4 Al that level, our new heider has over a factor of two salety maryill

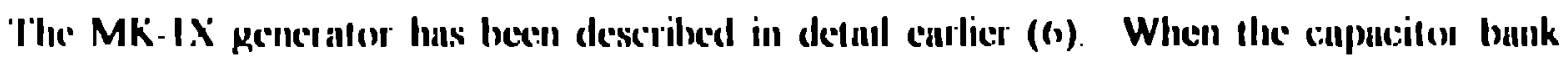

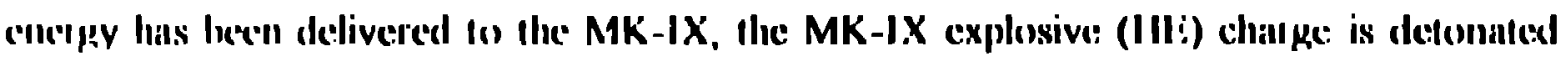

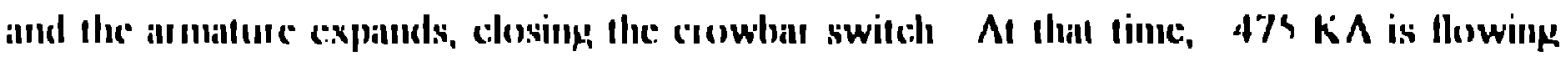

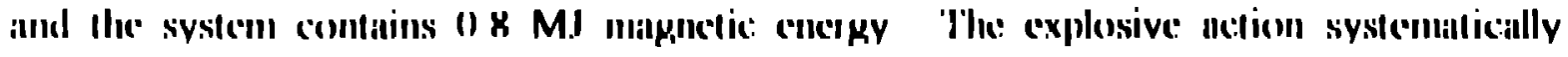

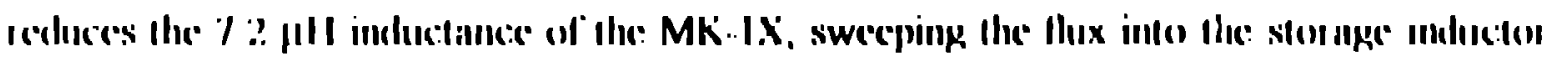

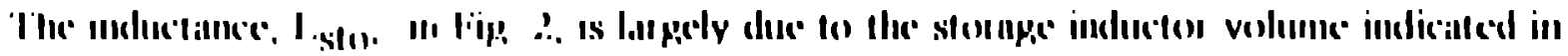

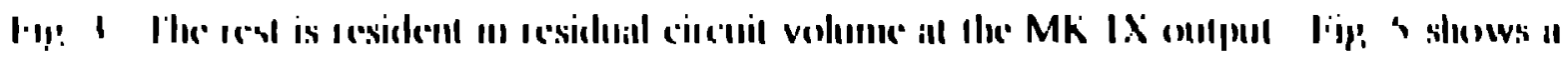

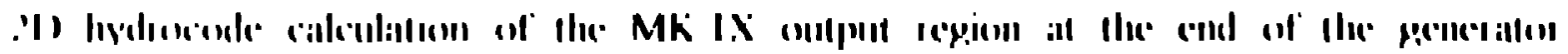

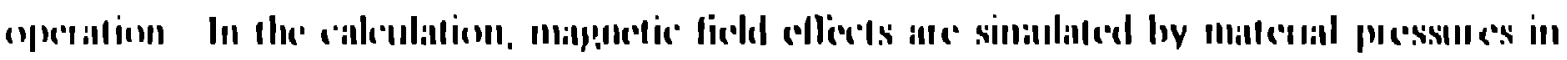

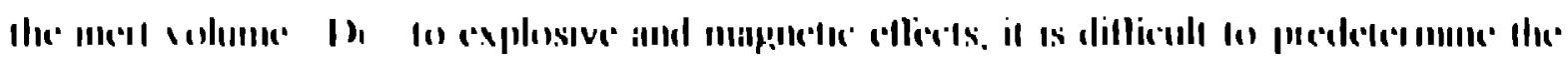


exact value for $L_{s t 0}$, but we are able to deduce the effective value from current transler ratios. On our recent test, a value of $79 \mathrm{nH}$ is obtained for $L_{\text {sto }}$, which indicates tha! the field has increased the circuit volume substantially. In addition, the free volume at the end of the MK-IX allows the HE pressure to be relieved, and causes the armature to be retarded somewhat. The storage inductor for the Procyon device was designed carefully to avoid problems associated with high pressure magnetic field effects. Current joints are designed such that pressure brought to bear by the joint bolts equals or exceeds the magnetic pressure. In some cases material strengths are exceeded, and an eflort is made to provide inertial confinement for the time scales of interest in these cases. In the storage inductor, material strengths are exceuded for approximately the last $35 \mu \mathrm{s}$ of the pulse.

We have previously described the lifili in a variety of publications $(10,11)$. Fig. 6 shows a 21) hydrodynamic calculation to help summarize the opening mechanism involved in these switches. Seggnents of a conductor that has adecpuate cross section to conduct a current pulse without fising from (Ohmic healing are exlruded into a cross section that will fuse, producing the resistance, R R:IFl, in ligh 2 . We have used lifili switches in last applications where Ill: is direcely in contand with the sevilch element (12). Subsecfuemly, we have demonsituted that they can be slowed down by substituting inert material adjacent lo the swilch element, lercing the explosive to drive a larger mass (11). 'This is the conligun ation

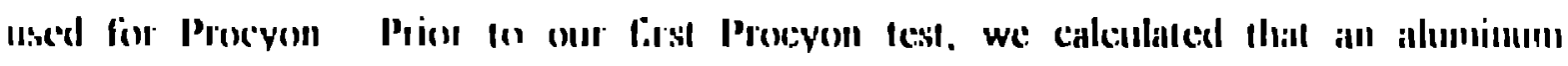

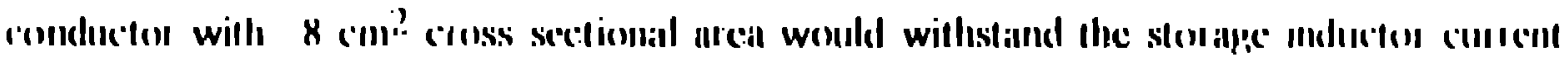

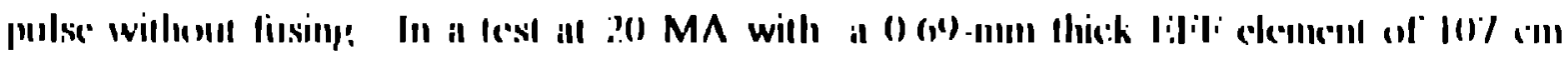

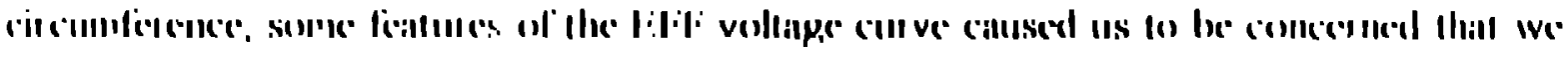

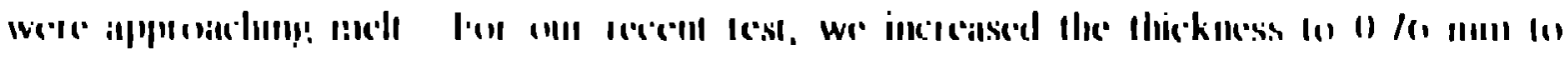

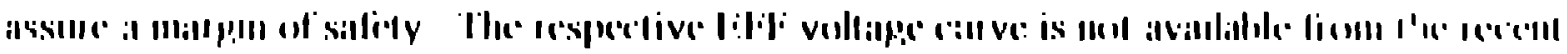

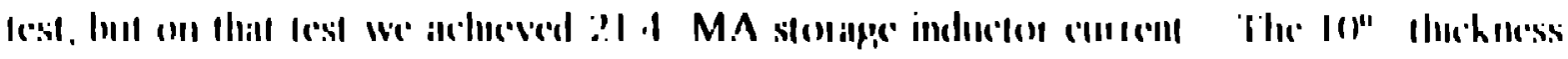

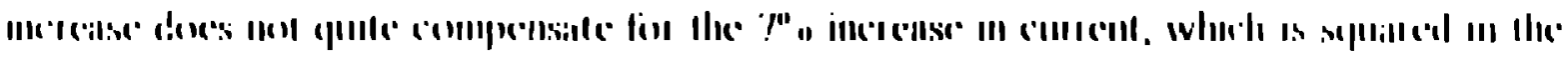


action integral. Nevertheless, inordinate losses were not encountered, even at the end of the current pulse, so we are confident that we have not passed the action linit for the Elil: element. However, another 10\% current increase could dictate an increase in Lilip thickness

We surmounted several engineering design dilliculties with our litil elemem by manufacturing it out of a single forging. By this nethod, we avoid clamping the thin material in a complicated high pressure joint, and are able to fare the thin wall into a thick end plate with a machined curve. We were initially concerned about that junction (1). but the eechnicpue has proved satislactory.

\section{'Yransfier S'ection}

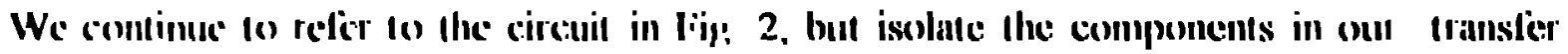
section in lïg 7 'The components of this trinxinl section are pictured in lijg 8 . In the fippure, we note a conxial llansmission section with a vaceum dielectric: intedince at one end

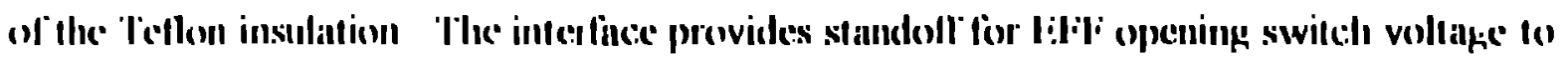
drive courcent inlo the vacumsm repion, and balless isolute the interfiate fiom radiation

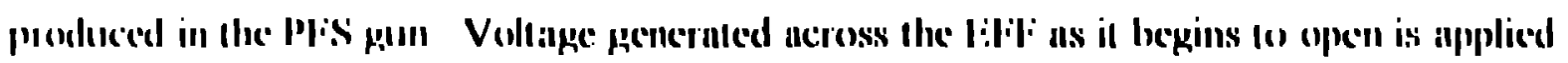

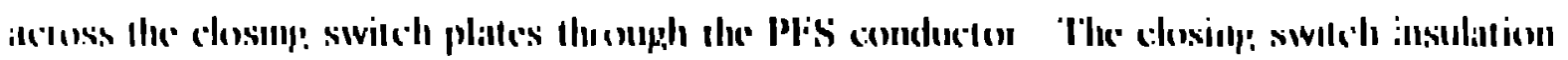

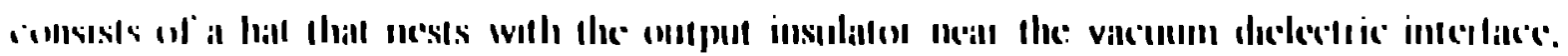

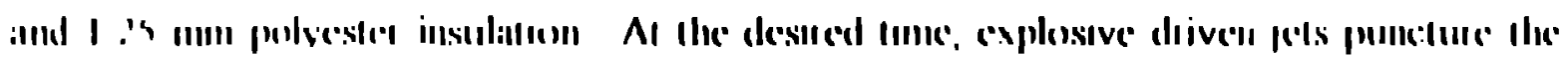

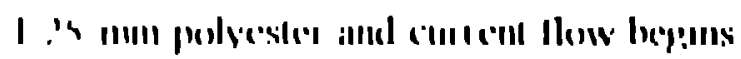

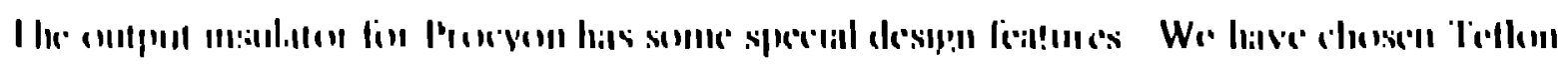

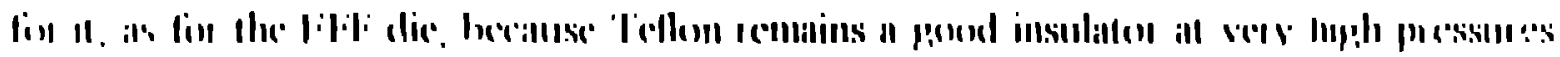

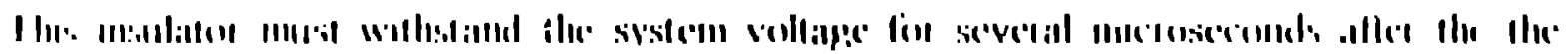


shock wave has passed through it, and has distorted it considerably. The section at the output end of this insulator was designed carefully to prevent the explosive action from shearing it and causing a high voltage failure. In addition, we made the insulation $11-\mathrm{mm}$ thick in spite of data indicating we could hold off $140 \mathrm{KV}$ across $6.35-\mathrm{mm}$. As seen in Fig 7, the output insulator is nested with the closing switch hat to provide a long path between switch plates at this junction. Finally, the vacuum dielectric interface on the output insulator was incorporated in electric field calculations performed for the radiation bafle/interface section. We arranged ficld contours to be perpendicular to the vacuum interface, and the highest field points in the bafle region were $250 \mathrm{KV} / \mathrm{cm}$. liurther, practical experience suggests at least 5 bounces should be provided by a baflle system, and our baflles were designed accordingly. There is also information that suggests that radiation should be kept below $60 \mu \mathrm{J} / \mathrm{cm}^{2}$ (1.3). By coupling attenuation measurements with RMIII) calculations, we estimate that we expose the Procyon interfice $1010 \mu \mathrm{J} / \mathrm{cm}^{2}$ (14) 'Ihe atlentuation measurements were made with light between .100 , and $600 \mathrm{~nm}$ in wavesength, however, but for IIV light the attenuation is much preater. 'Therefore, the IIV racliation that is responsible for the llashover is much less than the $10 \mu \mathrm{J} / \mathrm{cm}^{2}$. We have: previonssly de'seriloed our system of six explosively actualted closing switches (2) in pan allel Be("Iuse we have: iarge explosives cilarges in olher components, we are liree to use as much III: as needed on drive high quality jets As a result, we achieve gond synchronizallion, jitter

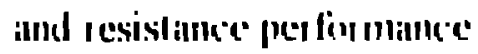

Mis

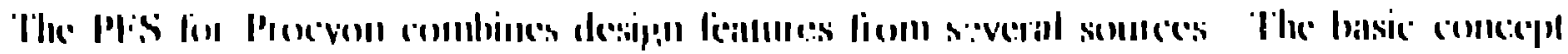

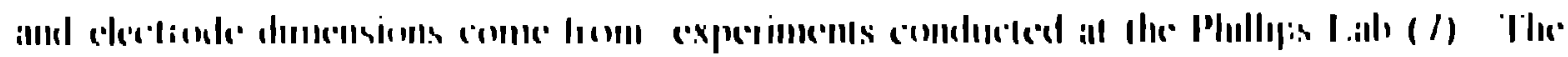

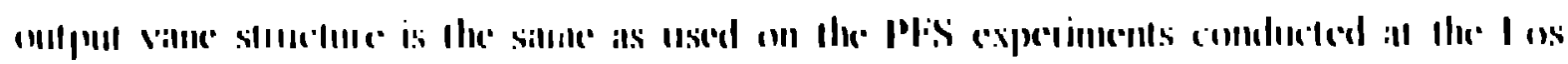

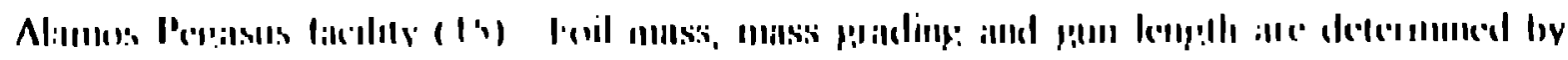


coupling early Procyon results with a variety of calcellations, and a paper dedicaled to these eflons also appears in these proceedings (8). Recent tests on the legasus bank and our recent Procyon test employed a mass graded foil for the initial Plis conductor. lïg. ") shows the miss distribution in the foil, and Fig. 10 shows the foil installed in the shot. The mass distribution in the aluminum is roughly $1 / r^{2}$, and when coupled with the .3 .36 fum thick mylar barrier lilm forms a $1 / r$ mass distribution.

\section{PIILSIII) POWI:R (ONSII)IIRATIONS}

lïgure $I$ is a simple circuit that helps summarize pulsed power considerations. If a constant $I_{(0}$ is flowing in the loop with constant $I_{\text {st }}$ and $R$ when the switch, $S$, is closed. Hhe'll

$$
\begin{aligned}
& l\left(\begin{array}{c}
1 \cdot 1, \\
1 ., 1,1,1,1.1
\end{array}\right) !(1, \cdot \cdots)
\end{aligned}
$$

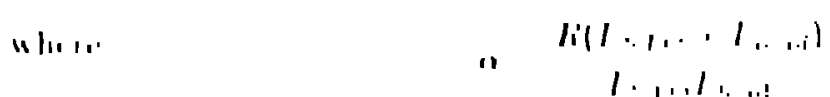

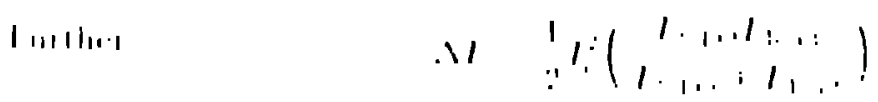

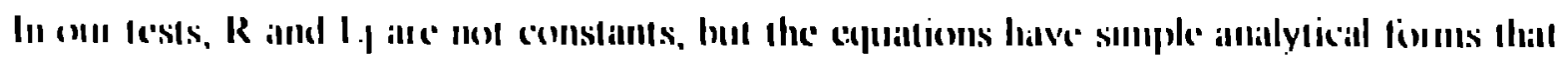

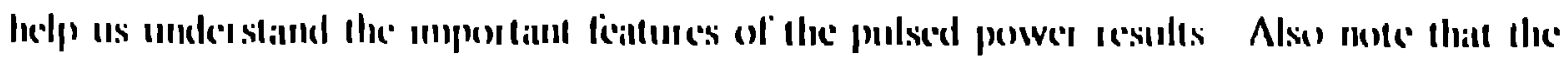

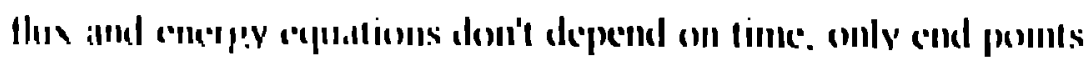

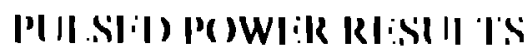

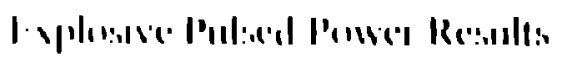

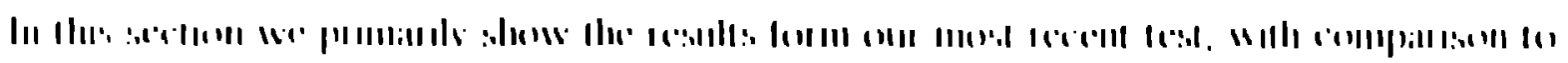

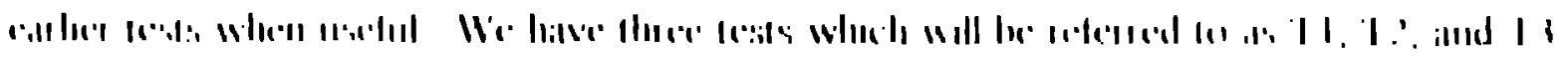


respectively for ease of identification. $\mathrm{Tl}$ was our earliest test, and was conducted at $\sim 10 \%$ lower than nominal current. T2 was our first attempt at a rominal energy experiment and it experienced a transmission line failure because the closing switches were not adequately synchronized with the EFF. Important data came out of T2, however, $(2,3)$ and it was this test that provided most of the insight for subsequent design improvements. T3 is our most recent test. It is another nominal energy test, and system improveinents provided an additional $7 \%$ in storage inductor current over T2. Fig. 12 shows $I_{\text {sto }}$ plotted for all three tests. The spike at the peak of these curves is due to flux compression in the EFF, and we will refer to the current just prior to the spike as peak storage inductor current. On $\mathrm{I} 3$ at that time, with the derived $\mathrm{L}_{\text {sto }}$ of $79 \mathrm{nH}$, we have $18.1 \mathrm{MJ}$ available in the inductive store. Unfortunately, ground loops present on the test affected high sensitivity signals, and there :s uncertainty in our initial current. The curve in Fig. 12 derives from Faraday rotation data (16) which is not affected by ground loops. Redundant sensors are available to generate the 'T3 curve, but signals were ofl' scale duing early times. We have shifted the 'T3 curve up by $0.511 \mathrm{MA}$ to account for initial current and early MCG multiplication. This shilt makes the T'2 and T.3 curves coincident at $200 \mu \mathrm{s}$, which is a reasonable approach since both tests were fired with $18.4 \mathrm{KV}$ on each bank module. The 'T3 curve demonstrates better generntor gain and suggests that system improvements helped. Calculations indicate that the increased Iilip element thickness accounts for a small amount of improvenent Additionally, the current joint between the MC ' $\mathrm{i}$ and storage inductor was observed to be glowing brightly at the end of both 'T't and 12 . Prior to 'T3, thi.s joint was redesigned, and framing, camera dalat revealed no glow at the joint on T!

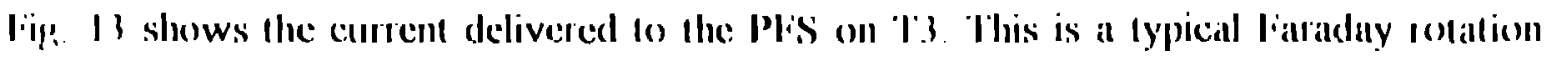
probe signal, and is one of three localed in separate places belween the clesing switches and

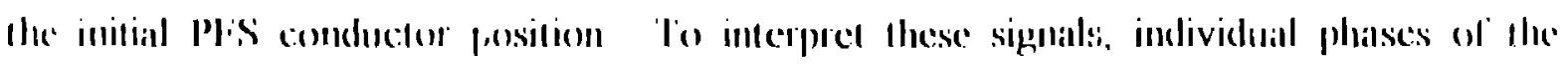
signals were analyded, taking, advannage ol cuadralure inlormalion, in some catses, and in

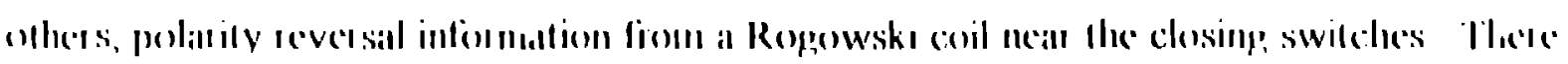


are minor differences between signals, but agreement among them allows us to say with confidence that $164 \mathrm{MA}$ was delivered to the PFS. The $10-90 \%$ risetime of this curve is $1.56 \mu \mathrm{s}$. Preshot ralculations used $20 \mathrm{MA}$ peak for $I_{\mathrm{sto}}$, and a combination of early and late EFF resistance profiles from $\mathrm{T} 2$ and $\mathrm{T} 1$ respectively. These were the best emipirical data available prior to $\mathrm{T} 3$. These calculations predicted a rise to $15 \mathrm{MA}$ with a $10-90 \%$ time of 2. $1 \mu \mathrm{s}$. The higher and faster current rise that occurred had interesting effects on the PFS switch performance as we will discuss later. With 16.4 MA flowing and the PFS plasma advanced $\sim 2-\mathrm{cm}$ downstream, we have $79 \mathrm{nH}$ in $\mathrm{L}_{\text {sto }}$, and $\sim 24 \mathrm{nH}$ in the load circuit. At that time we have $13.9 \mathrm{MJ}$ stored energy, and $\sim 1.7 \mathrm{MJ}$ inside the vacuum.

liig. 14 shows $\mathrm{d}\left(\mathrm{I}_{\text {sto }}\right) / \mathrm{dt}$, a signal that is very important to the understanding of $\mathrm{T} 3$. We have marked several specific points on Fig. 14. The sudden increase in $\mathrm{dl} / \mathrm{dt}$ seen at $\mathrm{A}$ indicates the $\mathrm{GFF}$ element has begun to move into the forming die. The noise on the signal at $B$ conveniently denotes closing of the detonator switches. $C$ marks the peak negative swing in $\mathrm{d}\left(\mathrm{I}_{\mathrm{sto}}\right) / \mathrm{dt}$ while the current is being transferred into the PFS. D and li rellect final stage vacuum switching results. D is the time at which flux suddenly begins to lill the remaining load volume, and $\mathrm{J}$ is the time of peak transter

liyg 15 shows d(lplis)/dt as determined from Iaraday and Rogowski coil data. Initial and final segments of the signal are from Rogowski coil signals. The Rogowski coil signal gives a belter initial step, but it went off sciale because of the ground loop. The peak of the signal is liom liaraday data l3y perlorming a crude smoothing on the curve, we estimale that the peith of this signal is I I MN/frs. By joining these I wo curves we have learmed that the

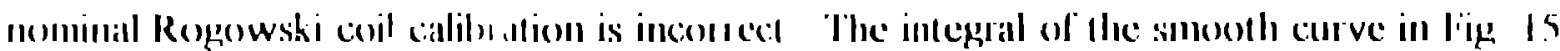

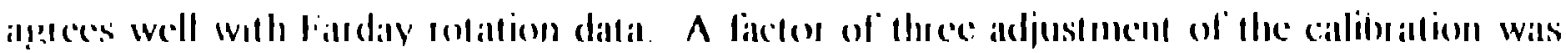
mecessialy lo accomplish this, however We are searching lon sources fien this error, but 
believe that the interpretation shown here is correct. 'There is further corroboration in our analy is of $R_{\text {IifF }}$ that will be presented later.

Using the signals in Figs. 14 and 15 we car make a self consistency argument to help determine the amouni of inductanee reduced in $\mathrm{L}_{\mathrm{sto}}$ and added to $\mathrm{LPF}_{\mathrm{S}}$ by the lelif llux compression. Since peak $\mathrm{d}\left(\mathrm{I}_{\Gamma} \cdot\right) / \mathrm{dt} \therefore 11.5 \mathrm{M} \mathrm{A} / \mu \mathrm{s}$ at the same time as peak negitive $\mathrm{d}\left(\mathrm{I}_{\mathrm{sto}}\right) / \mathrm{dt}$ : $4.3 \mathrm{MA} \cdot \mu \mathrm{s}$, and since we hnow thr.t whatever inductance is taken out of the store is put into the PFS, we can detennine that 4 nll is the difference, and that $\left(I_{s t o}\right)\left(d\left(I_{s t 0}\right) / d t\right)=\left(I_{, P I S S}\right)\left(d\left(I_{P F S}\right) / d t\right)-320 \mathrm{KV}$, lhe: voltage across the lilil at peak

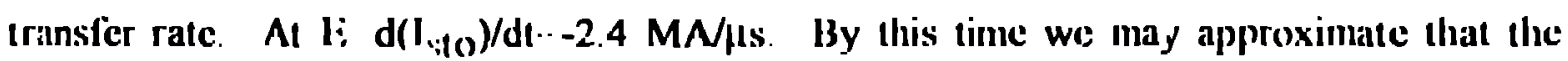

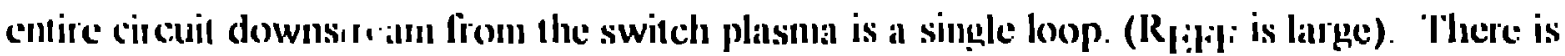
12174) nll upstretim from the vacum declectic inlerface, and with the plis plasmal eflictively 2.5 -cm down the gun barrel, we have 1111.5 nll between the l'pis plasmial and

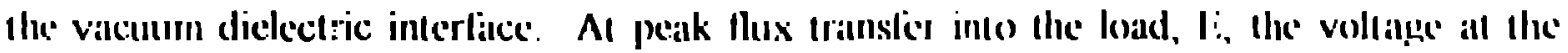
valeum dielectric interlace is $220 \mathrm{KV}$. The voltage that would callse the lilili lo restrike at lime $\mathrm{I}$ ! is $19(1 \mathrm{KV}$

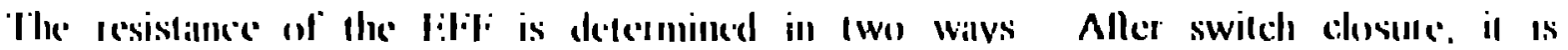
ilpuraximilled by

$$
\begin{aligned}
& \mathrm{R}_{\mathrm{I}: \mathrm{HI}} \quad 1 \ldots, 1, \ldots, \ldots \\
& 1 \therefore \quad / i:
\end{aligned}
$$

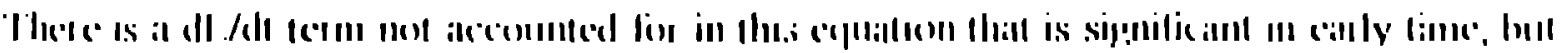

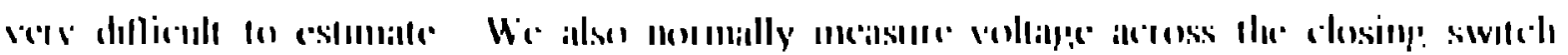

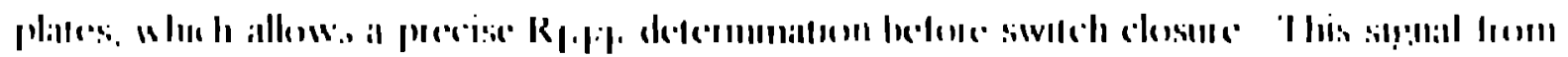

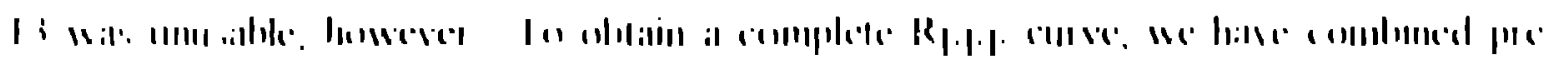
i

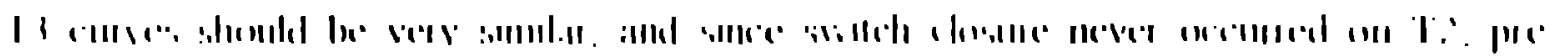


closure data extend well beyond what would be available from T3. After switch closure,

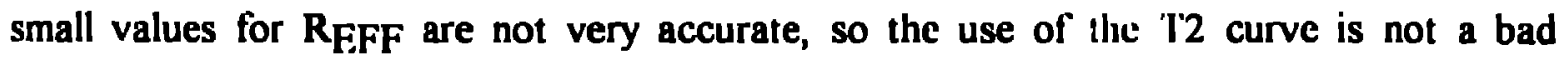
compromise. To combine the two curves we establisined the value for $R_{\mathrm{EFF}}$ when the closing switch actuated. This is done by measuring the initial step on the $d($ IPFS)/dt curve, then calculating the related voltage and dividing by ISTO. We then moved the T2 curve to agree at that time, and joined the curves. Our initial attempt did not procuce a good fit. After determining that our Rogowski coil signal was not properly calibrated, as noted in the discussion of $d\left(l_{P F S}\right) / d t$, we made the same correction for the initial $R_{E F F}$ value and obtained the fit shown in Fig. 16. The self consistency between these signals allows us to have confidence in this interpretation, even though we are not sure of the source of the error

Vacuun Swilching Results

The Procyon system combines an MC'( $i$ and two opening switch slages. We have descrilied the I:PP system that delivered $10.4 \mathrm{MA}$ to a PliS with $10-90 \%$ risetime of 1.6 fls. The timal pulse compression is provided by a PliS I)ala on PliS operation is available from I wo sources The Phillips Laboratory Shiva progham performed the pionecring work on the concept, and more recently we have been collecing dala on the los Alnmos Pepasus facilıtv( I5) A.s part of our program, 2I) RMIII) calculations are compared (n) the Shiva

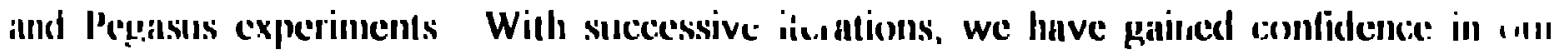

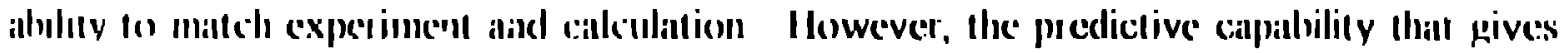

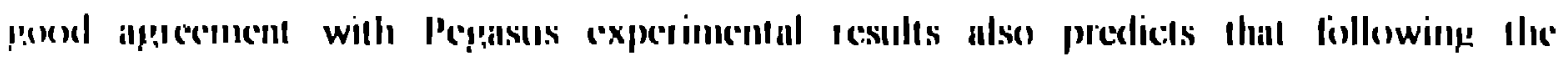

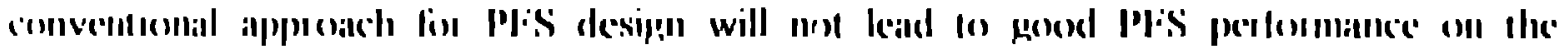

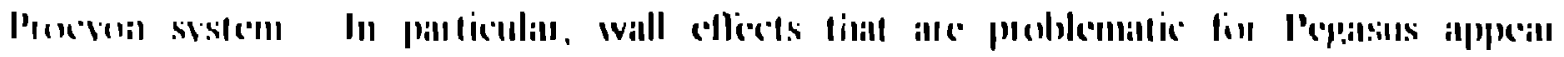

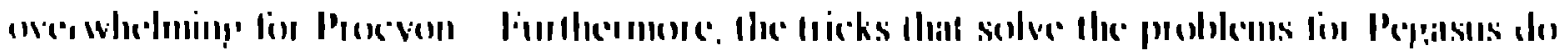

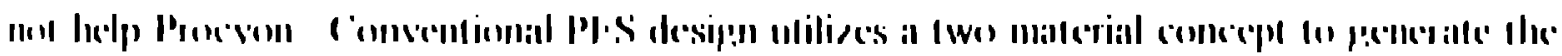


gun plasma. A low mass conducting material connects the two electrodes at the breach of the gun. This rapidly turns into plasma as current begins to flow. The second component is a plastic film that stops thermal plasma from flowing down the gun barrel until bulk plasma motion reaches that position. The sum of the masses of the two materials varies as $1 / r^{2}$ across the plasma channel so that the mass will be accelerated uniformly by the $1 / r^{2}$ Inagnetic force. In most work to date, the conductor mass distribution was generated by a cordal wire array, which could be varied by the number and size of wires and the cord angle. The plastic film is a constant density film. Recent developments have allowed the use of mass graded foil in place of wire arrays and Pegasus experiments have used a graded foil that varies as $1 / r^{2.7}$, which combined with the barrier film yields a $1 / r^{2}$ distribution. After a variety of calculations, a new scheme was proposed for Procyon. In this scheme, a $1 / r^{2}$ graded foil is combined with a barrier lilm to produce a total mass distribution that varies as $1 / \mathrm{r}$. For $200 \mathrm{mg}$ total plasma mass, we use $130 \mathrm{mg}$ of aluminum in the graded foil and $70 \mathrm{mg}$ in the polyester barrier lilm. Preliminary design calculations showed that this mass distribution, with higher pressure near the inner wall of the coaxıal gun, allowed the plasma near the inner electrode to get progressively further ahead of the plasma at the outer electrode liventually a mass thimned region occurs and flux rayidly flows through it. I sing datla firom early Procyon tests, the mass and gun length were chosen so that the rupsure would occur as the plasma was adjacent on the implosion load slot. A plasma trap in the inner electrode wall, as used on Pegasus (16), seemed (o) also help in the cilculations, but

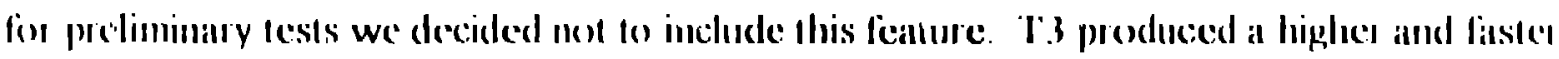

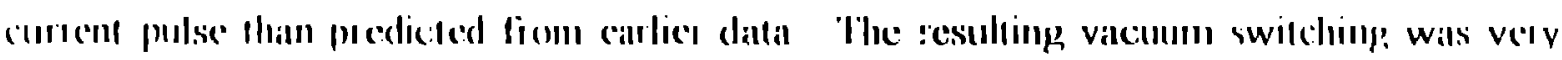

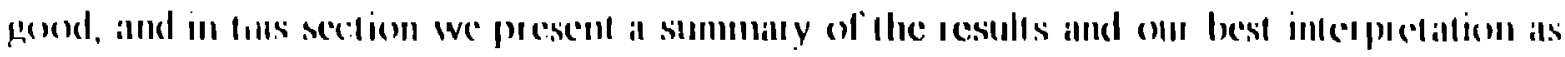

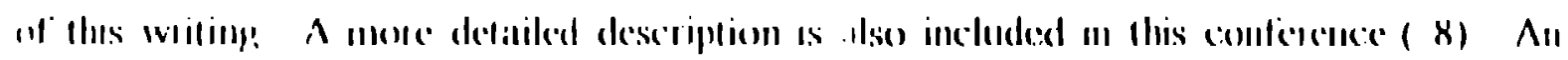

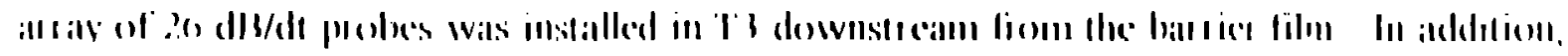

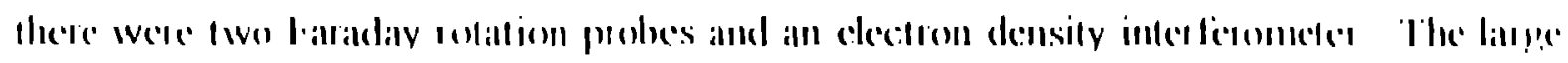

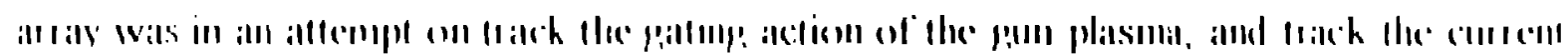


switched into the load slot. Fig 17 shows diagnostics locations. The ground loop on the test caused $\mathrm{dB} / \mathrm{dt}$ data to be very noisy, and not provide as much quantitative inlomation as we would like. A consisten! trend is evident, however. The tendencies indicated in preliminary calculations were born out by $\mathrm{T} 3$, but the increased drive current provided a diflerent over-all switching effect. 'The mass-thinned region occurred after the plasma had moved only $2-3 \mathrm{~cm}$ down the $7-\mathrm{cm}$ barrel, and llux flooded past the Plis and filled the remaining volume in only a few hundred nanoseconds. In addition, current rose 10 approxinately full values along the inner electrode, but not along the outer electrode. On those signals current appears to rise to some level, dips, then rises again slowly. One of the most exciting results was provided by a probe just inside the load slot along the upsticam glide plane This probe was positioned to discriminate between current flowing in a wall plasma that shorts out the load slot and current that is diveried, as desired, to lloe load. Subject to some interpretation. the probe shows that current rose to 15.5 with a $10-9(10 \%$ risetime af $5(10) \mathrm{ns}$, demonstrating that wall plasma did not short out the load The probes at the bottom of the load slot gave varying results, some of which recjuire some interpretation The most pessimistic interpictation comes from a db/dt probe that shows current rising 10

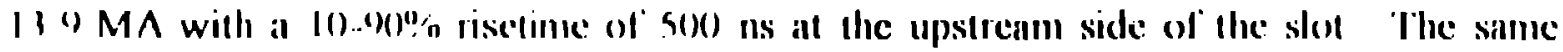

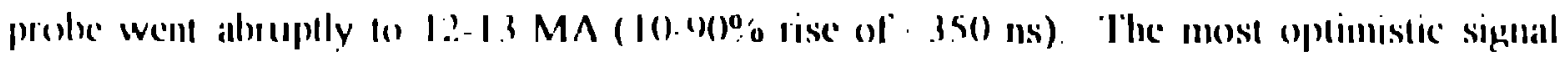

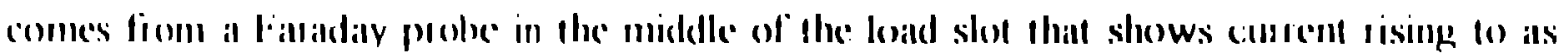

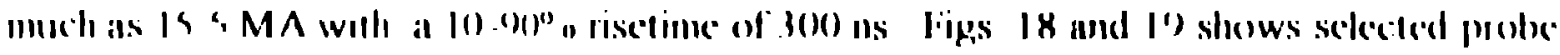

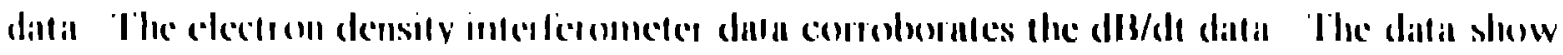

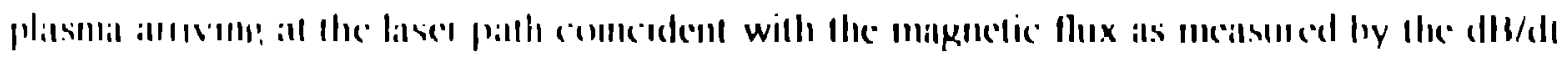

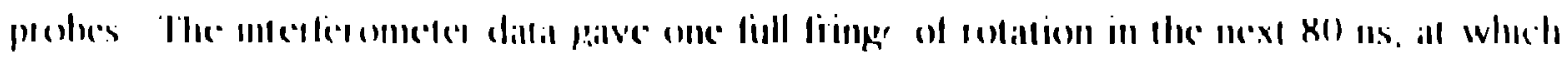

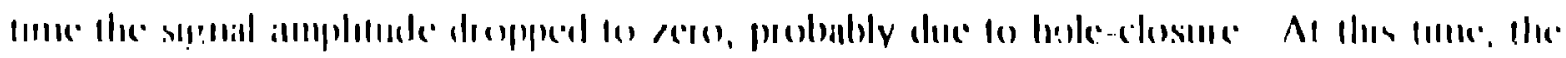

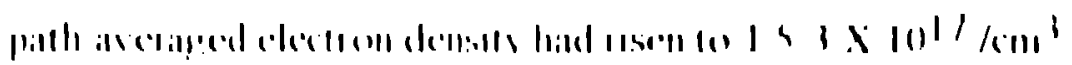


Calculations with the actual T3 PFS drive current arc currently underway to gain a better understanding of the test results. Initial calculations of this type provided severul qualitatively similar features, but failed to predict the over all result. Subsequent calculations were conducted with varying initial plasma conditions, and one set with generally good agreement has now been performed. lizure 20 shows the calculations at three time steps of interest. In these calculations the mass thinned region relcases the flux to the rest of the volume well within the barrel. Plasma then folds over and shunts current away from the outer electrode. Load slot calculations remain to be donc, and these should help with further interpretation of our load slot data

\section{CONCI.USIONS}

A wealth of inlormation is available firom 'l"3 asd we have not yet fully digested the results We continue to explore the relevant physics for a betler understanding of the vacuum swilching. Ilowever, the primary dilliculty encountered in calculations and earlier tests is the floceding of the load slot with plasma of suflicient density to returd the mugnetic: lickd flowing to the lond and add signnilicant (or overwhelming) mass to the implosions. The:

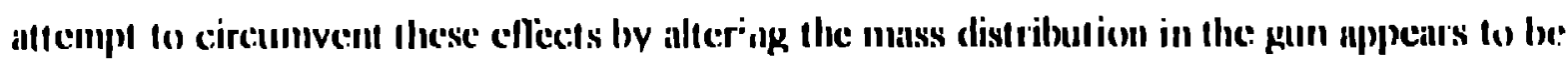
successfiul and we are preatly concenranged. (Our next eflonts will be lo explore:

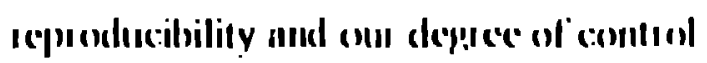

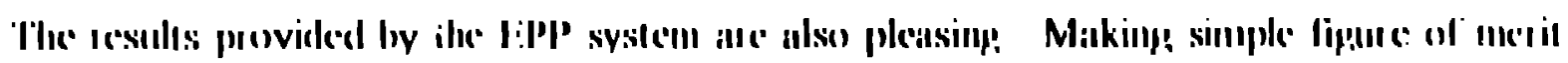

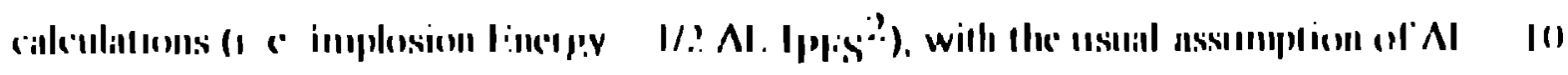

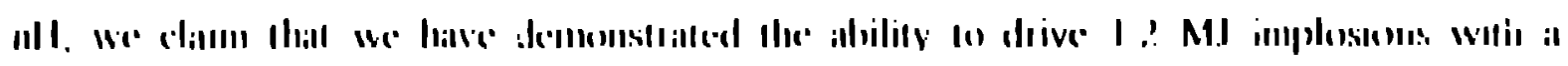

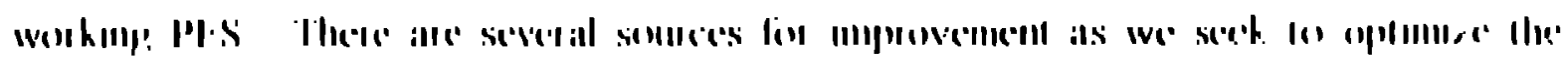

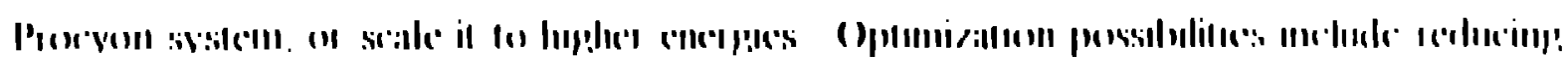


the thickness of our Teflon output insulator and reducing the over all inductance of our radiation baffles. We estimate that as much as $9 \mathrm{nH}$ could be eliminated and still have a working systen. This by itself would allow us to reach the $1.4 \mathrm{MJ}$ level by the standards use above. In addition, if the vacuum switching observed is sulticiently reproducible, then we can reduce the length of the PISS gun, and can further add to the inplosion drive current. On IY3, the total load inductance (from Eirl' to 4-cni radius load slot) was $30.6 \mathrm{nl}$. With 79 $\mathrm{nlt}$ storage inductance and 21.4 MA flowing, 15.4 MA should be transferred. 'This is in quite good agreement with the interpretation of our load slot liaraday sensor. With the optimized transnission line suggested above, we could ichieve 1.5 MJ. Finally, with no significant system changes we could take advantage of the full $20 \mathrm{KV}$ bank voltage available to us This should boost peak storage inductor current to 2.3.3 MA, and using all the improvements suggested above, we could transfer 18.9) MA, or have I.8 MJ available. IBeyond these limits, the size of the lifili would probably have to increase. Another I0\% current capactity is available, by increasing lifili dinmeter, witlout pushing our explosive manufacturing capability. 'This would recuire a ilghtly revised MC (i, but with the extra Io) o. we could transiler over 20 MA, and have over 2 MJ (o) work with

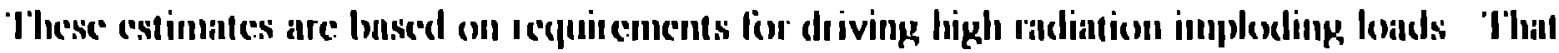
is. these londs recpuire radiation batlles and will probubly only achiceve a $\Lambda \mathrm{I}$, of

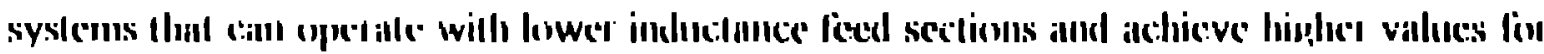

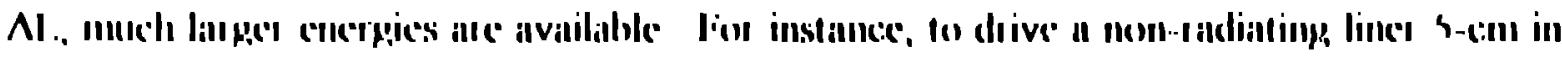

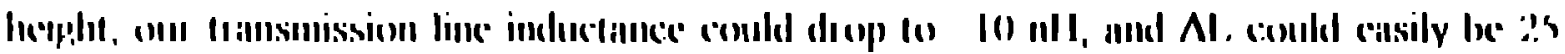

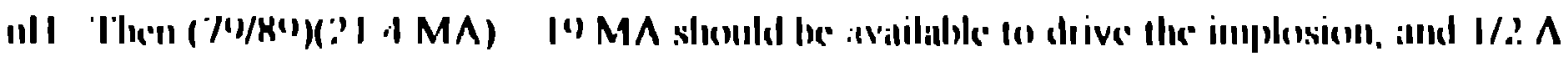
I I.' I I M

Rofincines: 
I. J. H. Golorth, R. S. Caird, C. M. Fowler, A. E. Greene, M. L. Hodgdon, I. R. Lindemulh, S. P. Marsh, H. (Ona, and R. E. Reinovsky, "Design of an Lxplosive Pulsed Power System for Driving 16-MA Plasma Flow Switch Experiments," in Proceedingss of the Megaganss Fields and Pulsed Power Sustems, 1989, V. M. Tilov and G. A. Shvetsov, Fds. (Nova Science Publishers, Ne:w York, 199()), pp. 651-658.

2. J. H. Goforth, H. (Mona, J. H. Brownell, A. L. Greene, H. W. Kruse, I. R. l.indemuth, S. P. Marsh, J. V. Parker, R. E. Reinovsky, D. (j. Rickel. and P. J. 'Turchi, "Procyon Experiments Utilizing Explosively-Formed lius: Opening Switches," in Prociedings of the 8th IEEE Pulsed Power Conference, 1991, R. While and K. Prestwich, lids., (|99)]), pp. 27.3-276.

3) J. H. Golorth, II. Oona, C. M. liowler, D. II. Herrera, J. C. King, and P. J. 'Turchi, "I:xplosively Driven Opening Switch for the 20-Megampere Procyon Lixperiments," in the' Proceedingss of the Sixth International conference on the (ieneratton of Megagrauss Magneter ic litelds, 1992, 10 be published

4. A. I. Cireene, R. I. Bowers, J. II. Brownell, J. II. Goforth, II. ()ona, I I. I. Pelerson, and I). L. Weiss, "(omputational Modeling of the Trailmaster Procyon System," (Ip. (ii. Refl, 2, pp). (64I-644.

5 I. R I.indemuth, R. It. Reinousky, and J. II. (ioforth, "I:xploding Metalic lioil I'use Modeling At I os Alamos," ()p. ('it. Rof' I, pp. 260)-274

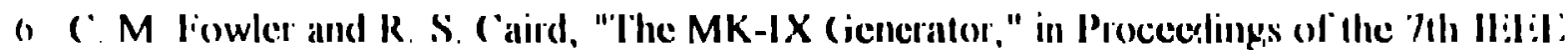
Pulsed Powe Conlerence, 1989, 13. 11. Bernstein and J. I Shannon, Lds , (1989), pp) 475. 178

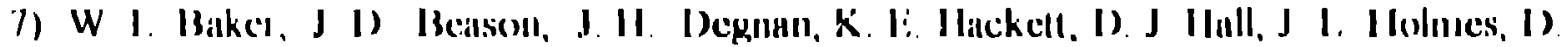

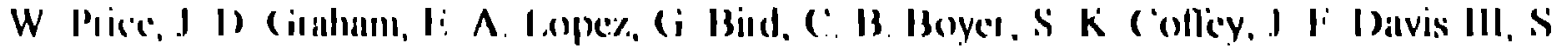

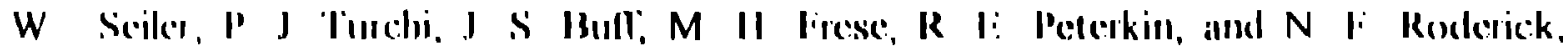

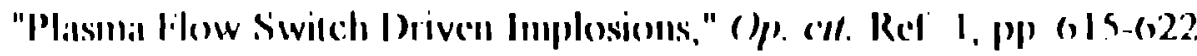

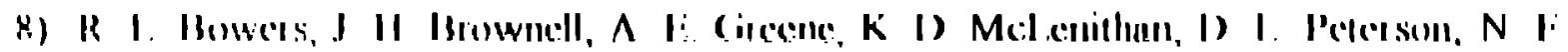

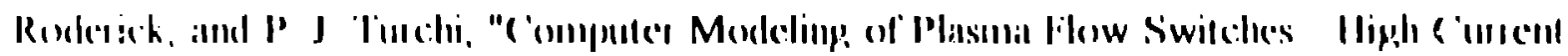

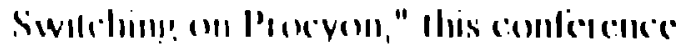

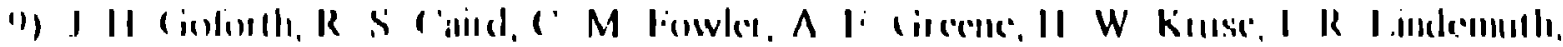

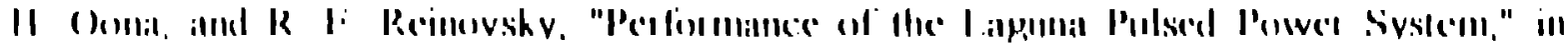

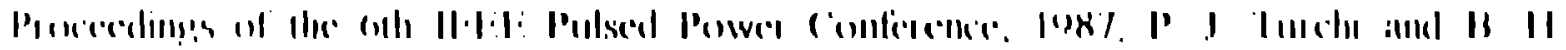

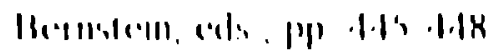

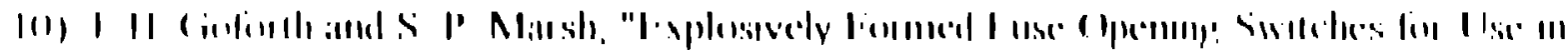

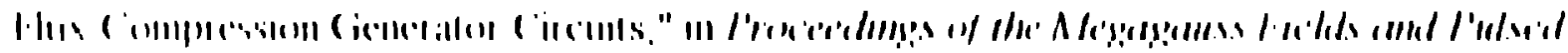

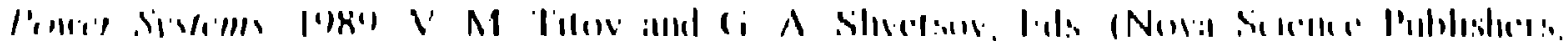

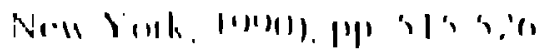


II) J. H. Goforth, I. R. Lindemuth, S. P. Marsh, and R. E. Reinovsky, "Lexperiments with Explosively Formed luse Opening Switches in Higher lifliciency Circuits," in Proceedings of the Seventh IEEFE Pulsed Power Conferc.ze, 1989, B. H. Bernstein and J. P. Shannon, eds., pp. $479-482$.

12) J. H. Goforth, II Oona, R. R. Bartsch, J. H. Brownell, R. S. Caird, J. C. Cochrane, D. J. Frickson, C. M. lowler, A. E. Greene, M. L. Hodgdon, II. W. Kruse, I. R. I.indenuth, J, V. Parke, R. E. Reinovsky, and R. J. Irainor, "Explosive Pulsed Power System for Driving I.aguna looil-Initiated Plasma Implosion Fixperinents,"

()p. ('ir. Rel' I

13) II. ()ona, B. G. Anderson, J. C.. Cochrane, C. L. Iïndley, J. H. (ioforth, A. LE. Greene, H. W. Kruse, J. V. Parker, and D. G. Rickel, "Plasma and Iilectrical Diagnestics lor Procyon lixneriments," Op. Cit. Ret. 2, pp. 6.33-636.

14) J. II Ciolorih, W. I: Anderson, R. R. Bartsch, J. I. Benage, R. I. Bowers J. :1. Brownell, J C. Cochrane, C. A lienstemacher, L. R. lioreman, P. R. Forman, C. M. Fowler, A. Li. Cireene, K. I. (iribble, II W. Kruse, J. S. I adish, C. M. L und, S. P. Marsh, K.D. Mclenithan, 'I. Oliphant, II. Oona, J. V. Parker, D. I. Pelerson, R. IE. Reinovsky, D. (i. Rickel, J S Shlachler, D. I. Weiss, li. Wysocki, N. I'. Roderick, and P. J. 'Turchi, "The I.os Alamos 'Trailmaster Program: Status and Plans," ()p. ('it. Ref. 1

15) J ('. ('ocliranc, R. R. Batsch, J. li. Benage, P.R. liorman, R Ii. (iribble. M. Y. P. Ilockadiyy, J. S. I adish, II. ( Dna, B. Paputheofimis, J. V Parker, J S Shlacheer, and If. J. Wysocki, "Plasma lilow Siwitch Iixperiments of Pegasus II," this conlerence

Io) I: J Wysocki, R R Bartsch, R I. Bowers, J. (' ('ochune, A I: (ireene, J S

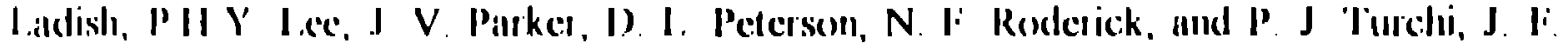

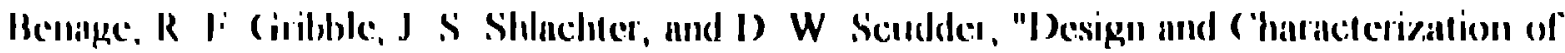
Ila. Pep,asus I Plasmal lilow Siwilch," ()p. ('it. Refl I 


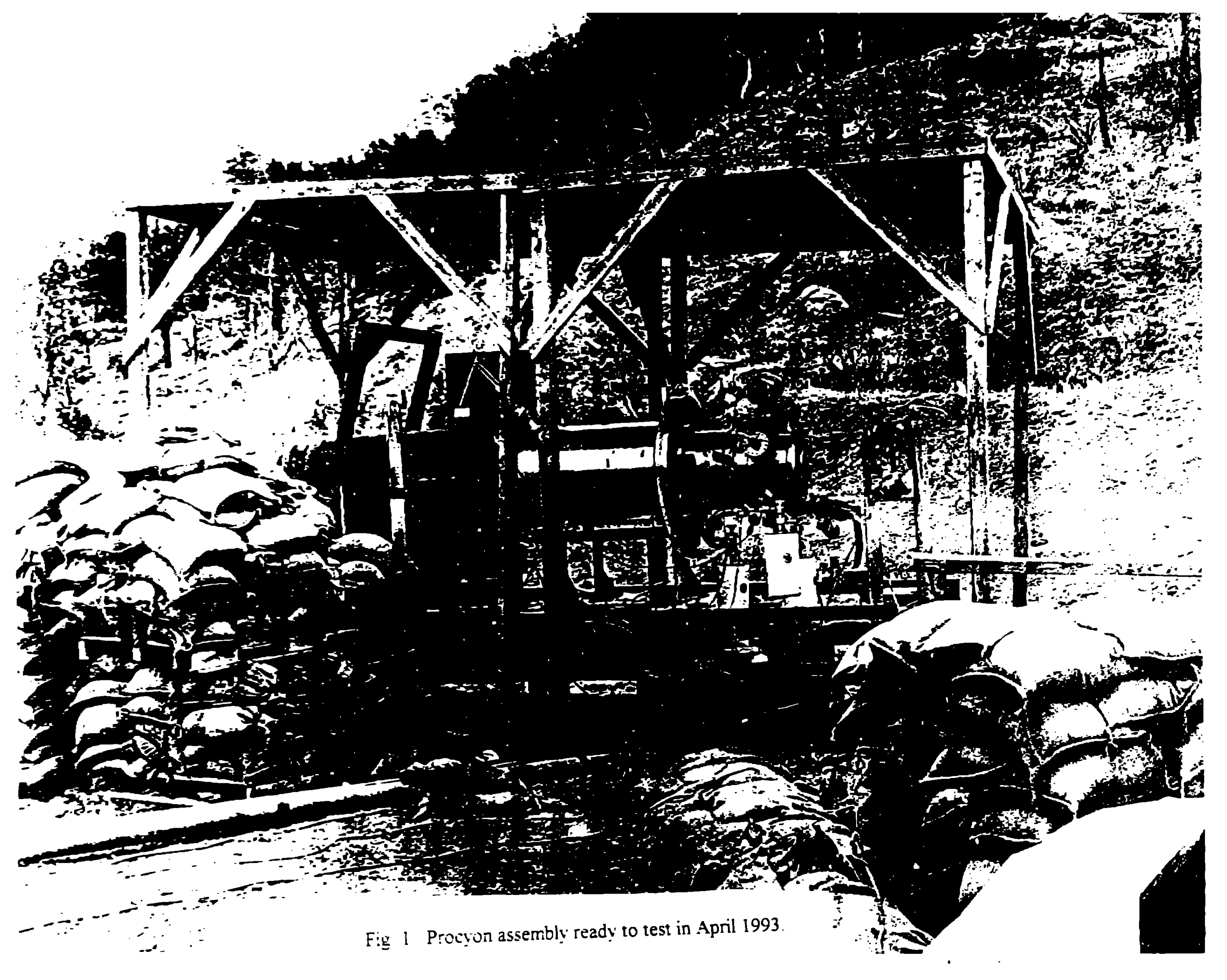


lïg. 2. Procyon circuit. $C_{1}$ and $C_{2}$ are (wo 3000 pll capacitor banks arranged in series with a special header. I,W and $R_{W}$ are cable and bank inductance and resistance. I'he $4 \Omega$ resister prevents lare! voltage reflections at the input to the MK-IX MC (i, I (j, when the switches $S_{1}$ and $S_{2}$ close. Mk-1X explosives close the crowbar switch, $S_{3}$, as the MC( $i$ hepins (o) operate I.ST() is the storage indectance inlo which the MK-IX drives .he maynenetic flux in the system. R Riliti is the resistance of the ligli epening swilch. When $\mathrm{S}_{4}$

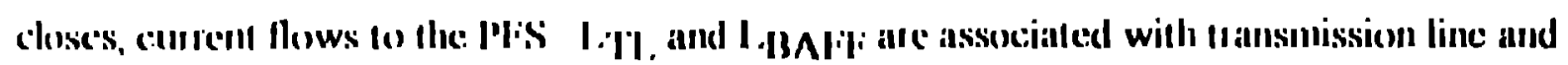

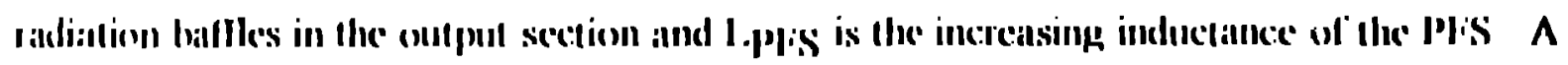
? (1 nll l loild is shown

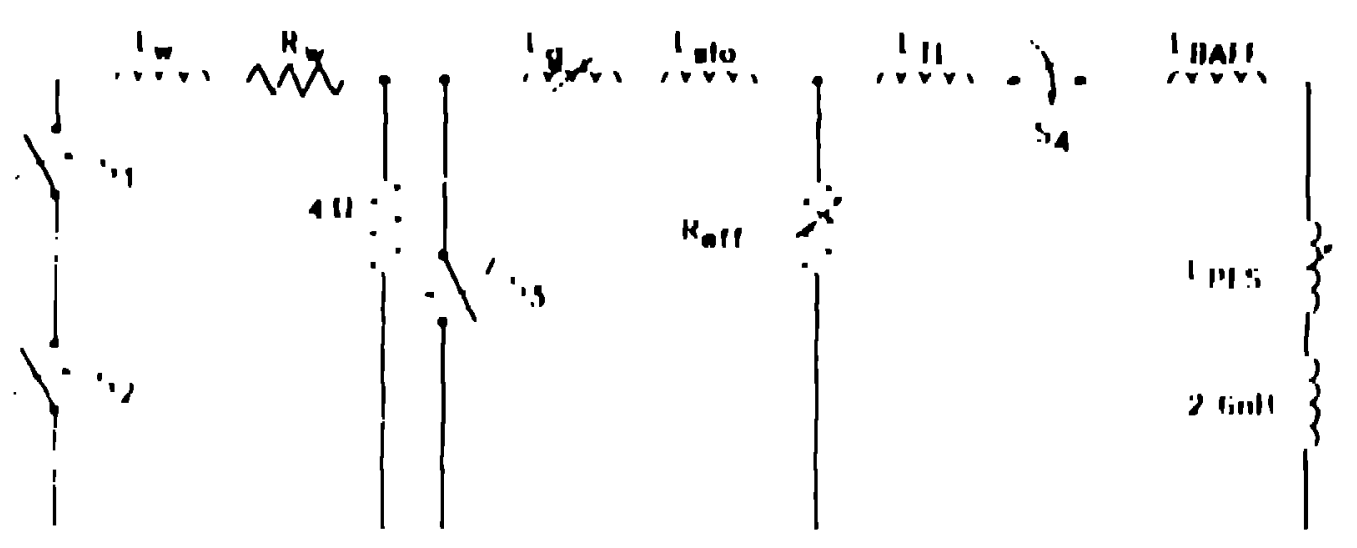




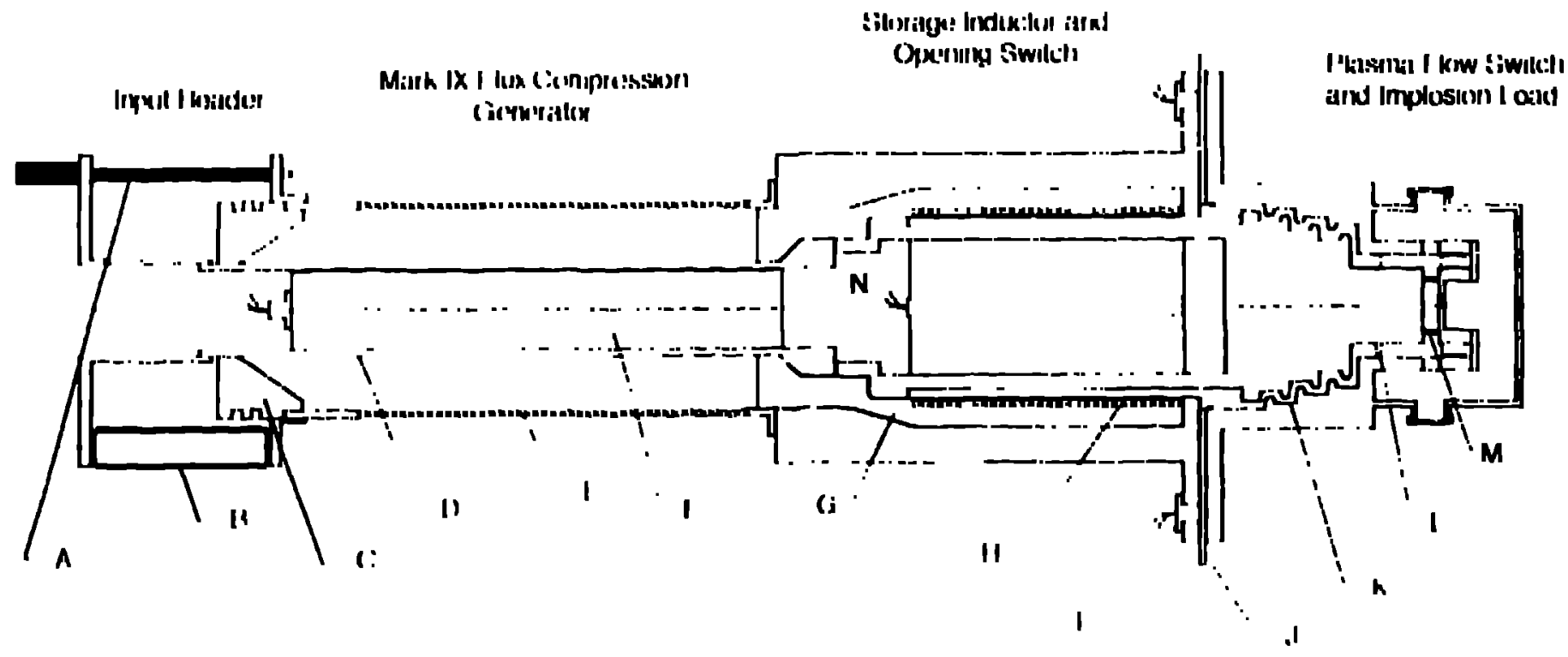

liig. 3. C'ross scastion of the Procyon explosive pulsed powed sysicm. The three major seyments are noted, as well as the input header and the components: A- 'Yypichl input cable: B- Typical resistor in a 4 S2 array, ('- Input insulator, D- MK-IX armature; it:- MKIX stator, li- MK-IX III:, (i-'Teflen Iilile forming die and stornge inductor insulator; I1-

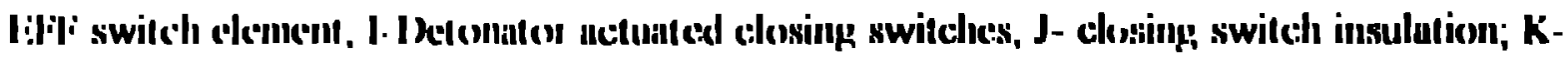

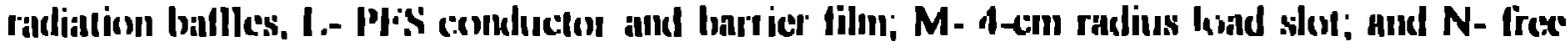

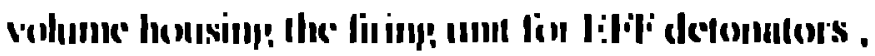




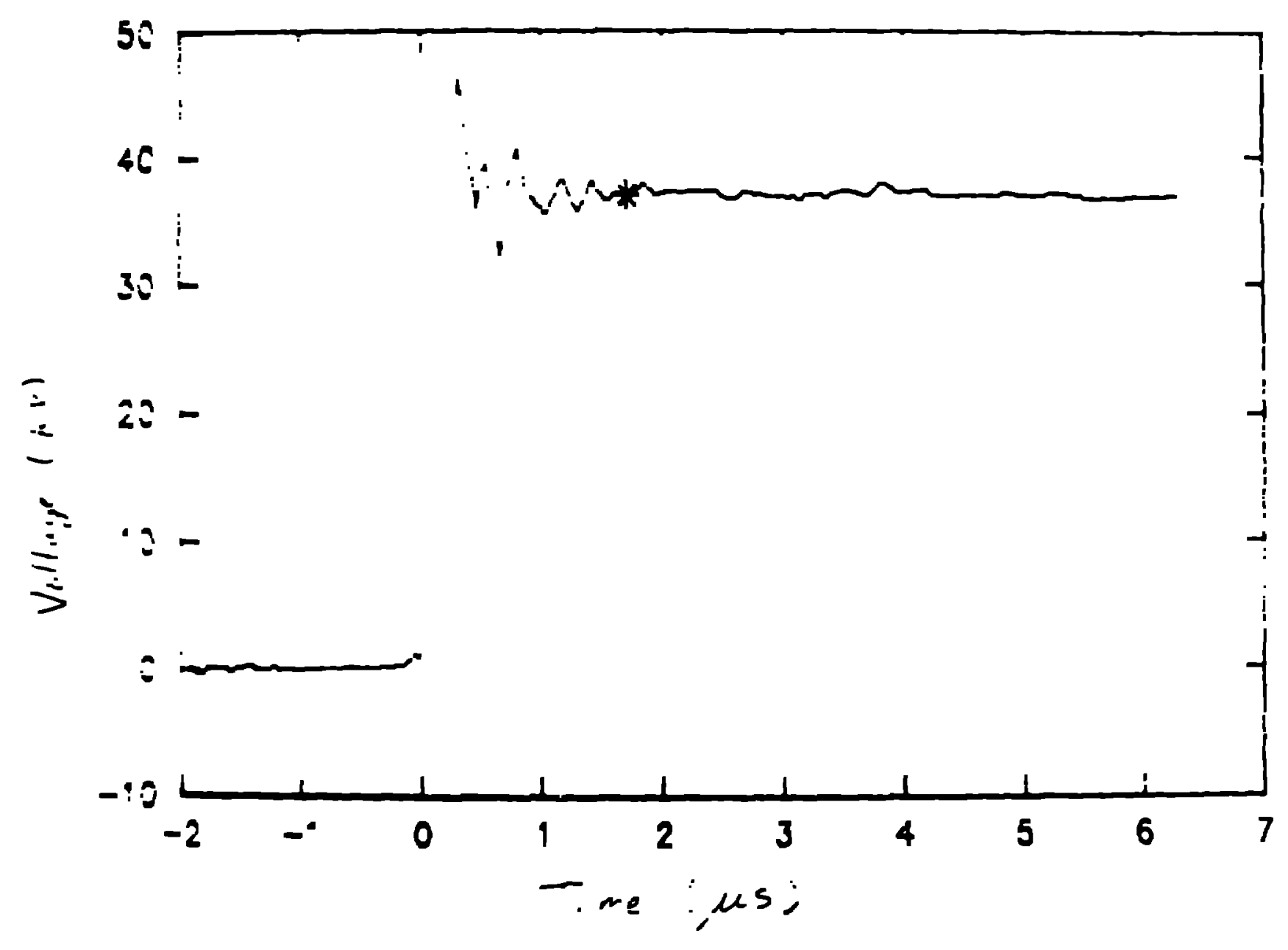

Fig - Voltage measured on a recent Proryon test at the Marx header. 


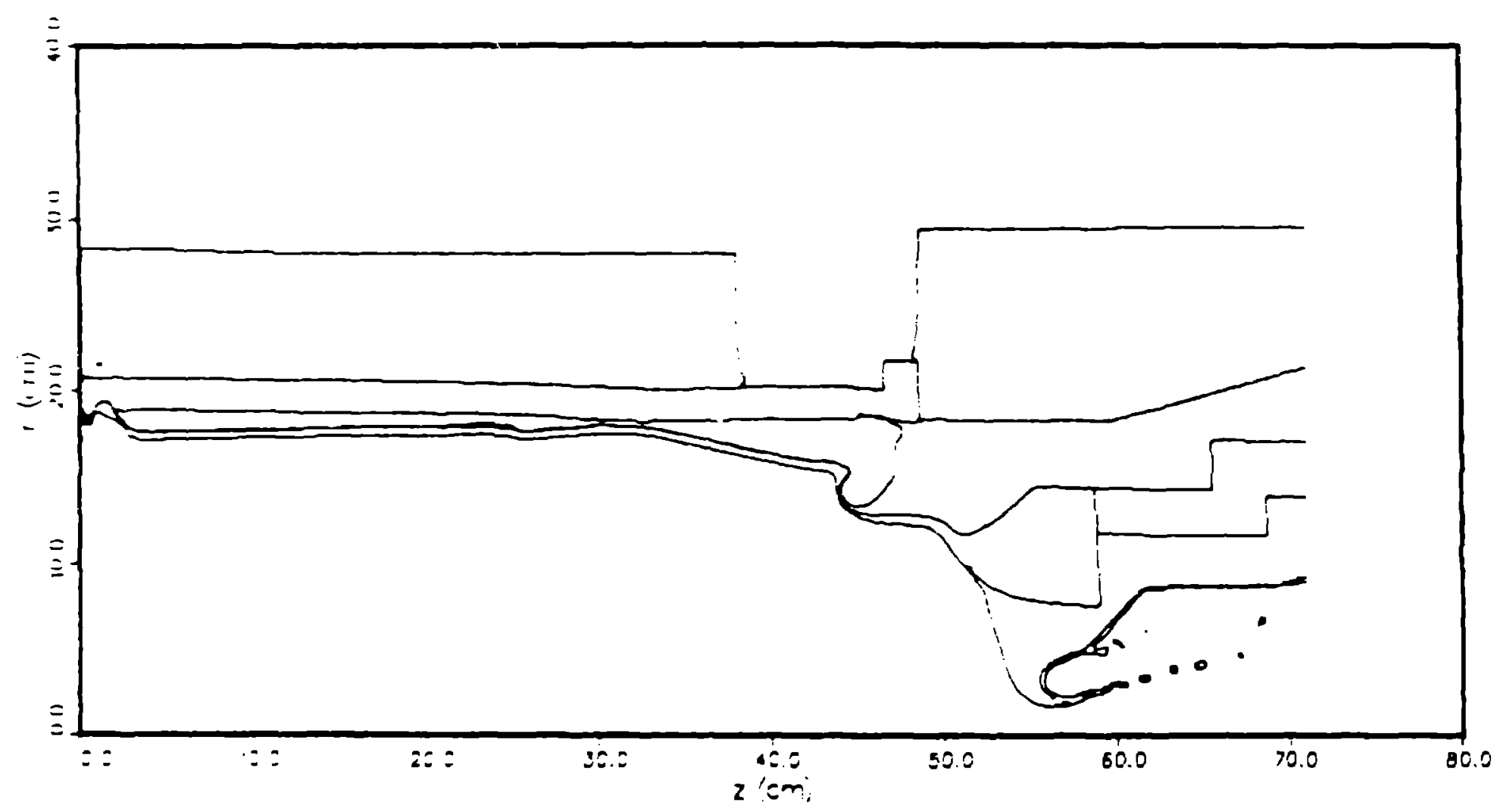

Fig : 2-D hydrodynamic calculation of late time MK-IX output configuration. 


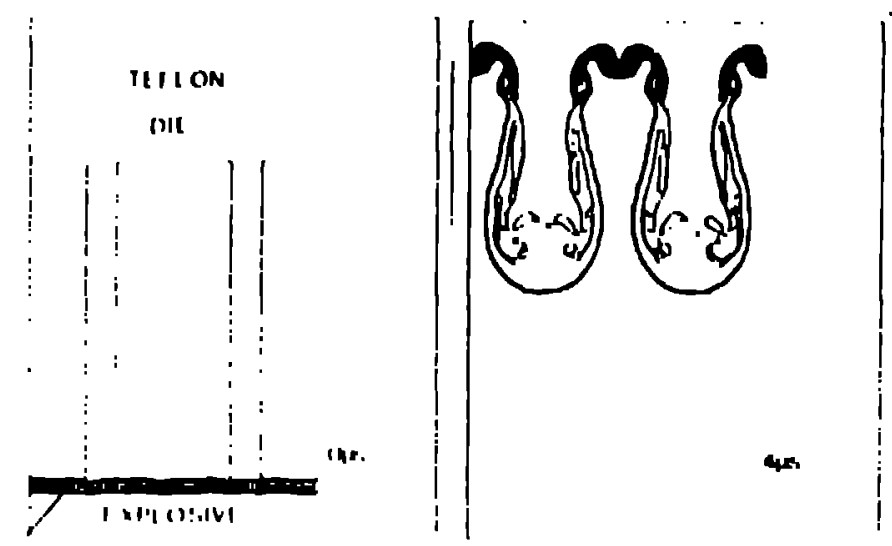

ligh. 6 Synopsis of I:lif pertiomance. 'Ihe aluninum shown at 10 is extruded into the shape shown al t 4 fls by the explosive. 'The thin sections of the lilifi will fisse firom (Dlunic: leating at an appropriate current density for Procyon experiments, the lilili switch element is an aluminum conduc:lor $(0.76-$ mm thick. The element is actuated while canying

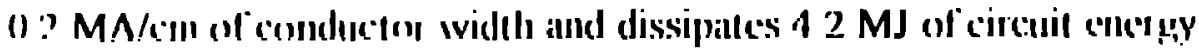




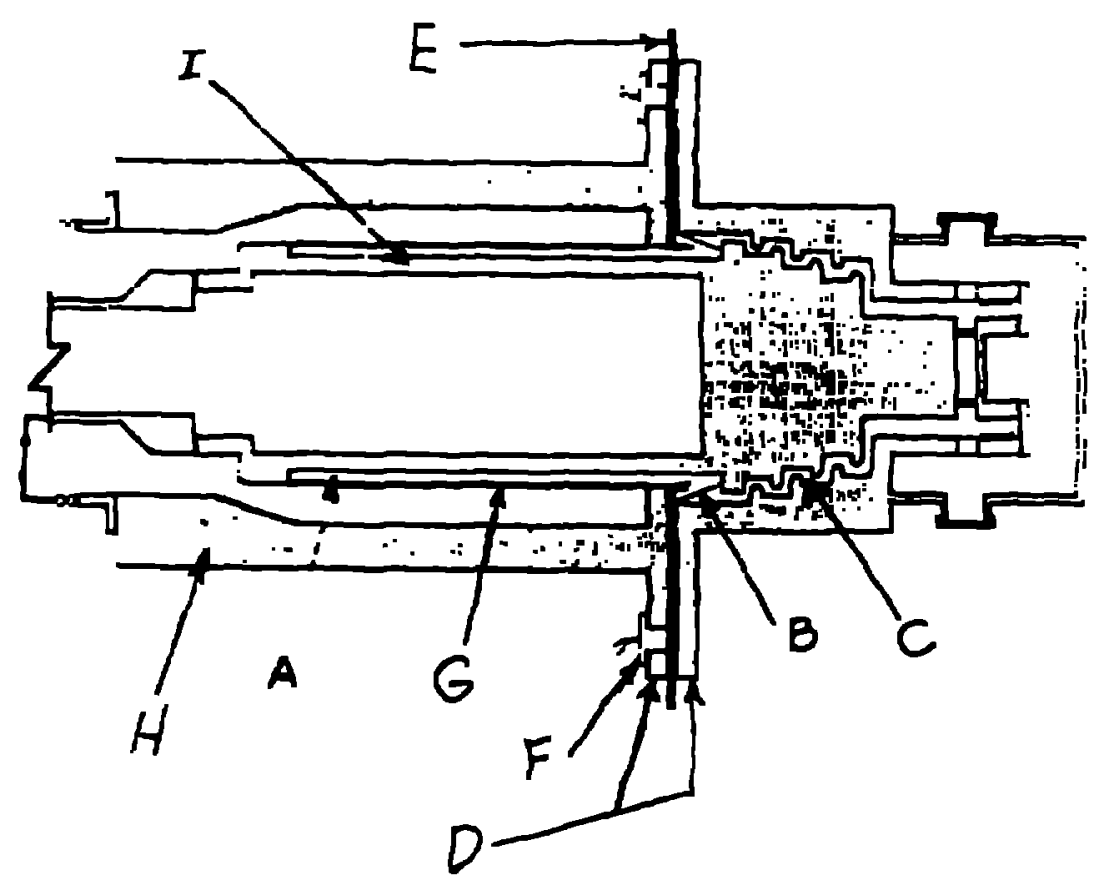

Fig : Transfer section A- Coaxial output transmission line insulator (Teflon); B- Vacuum dielec:ric interface, C- Radiation baffes to protect vacuum dielectric interface: D- closing swicch plates. F- nested insulator hat and $1.25-\mathrm{mm}$ polyester insulation: $F$ - detonator actuated closing switch (array of six in parallel); G- EFF switch element; H- Outer conductor of storage inductor; I- Output conductor. 


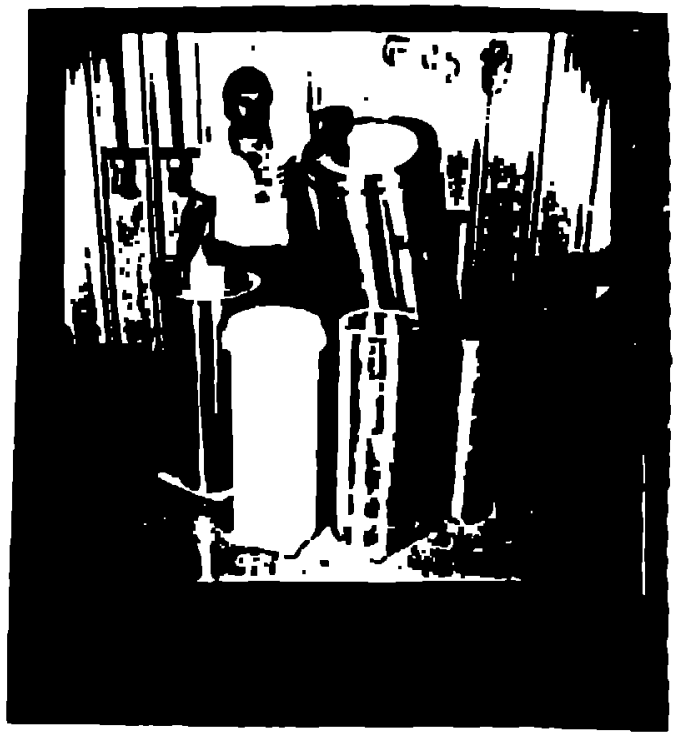

lïg 8 C 'ylindrical components of the Procyon transfer section Iirom lefl lo right on the fleor A. III li: switch element; 13- outpul insulator; (:- output condes:(or, 1)- air lens tior the III: system Mounted on the stankl is the onter wall of the stentige inductor with the lifili die and stor age indector insulator installed 
$\vdots$

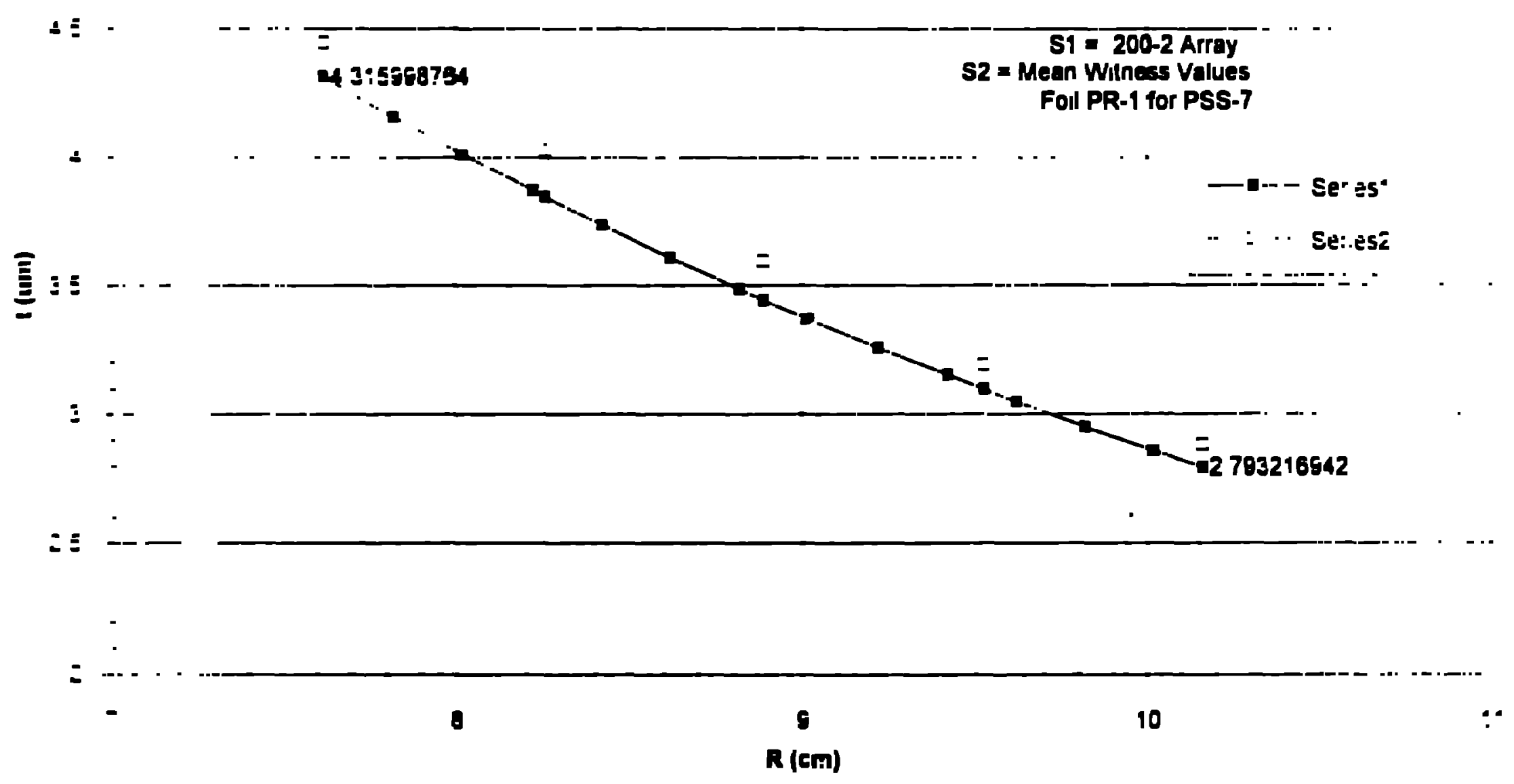

$F: z ;$ T:ieicesss projie for the Procyon mass graded foil. This distribution varies as $1 / \mathrm{r}^{2}$.

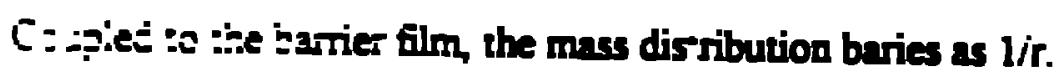




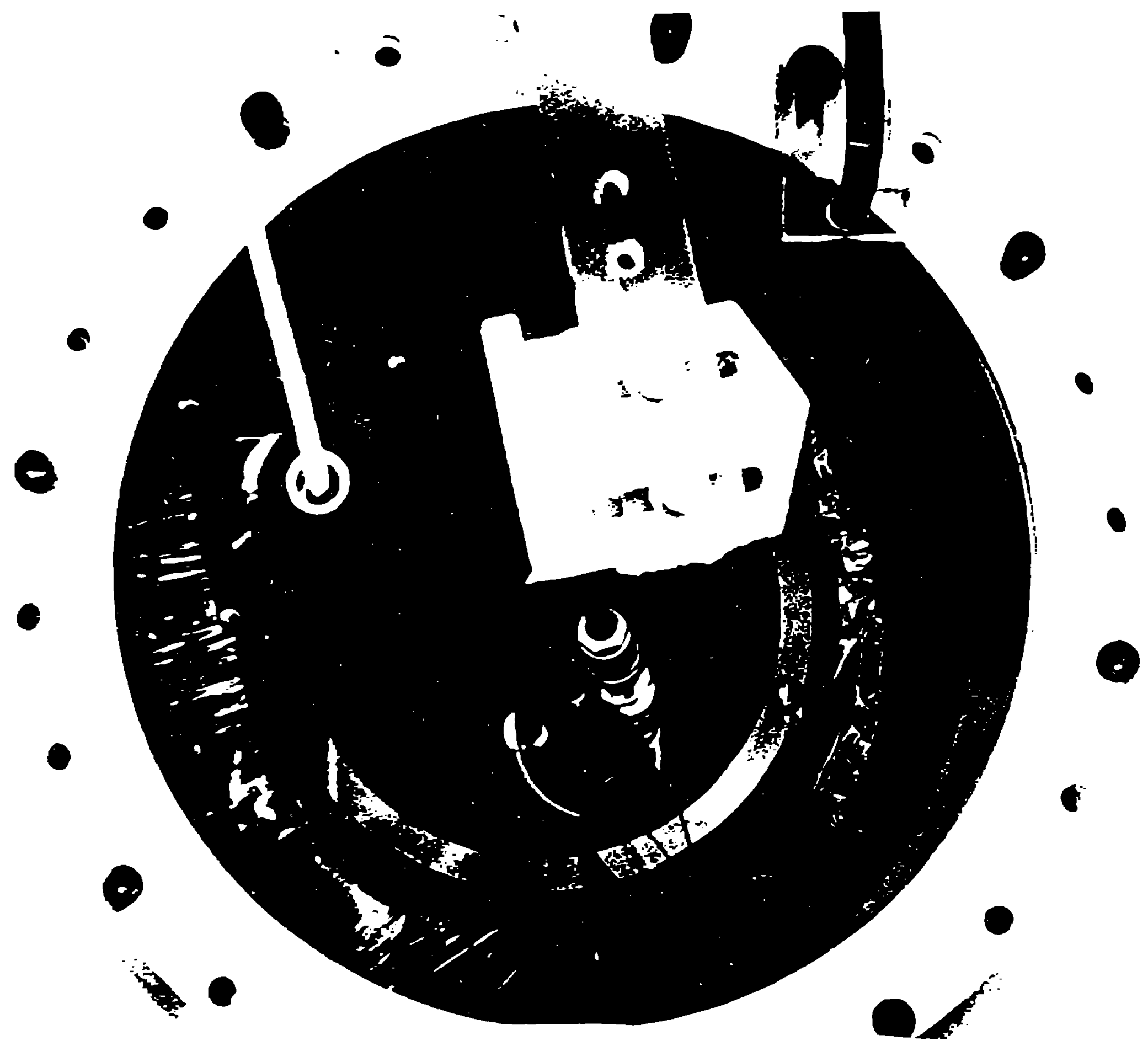

Fig ij End viex of the Procyon vacuum chamber showing the mass graded foil as istailed 
ligh 11 ('incuit fion simple analytical current transfer antylysis.

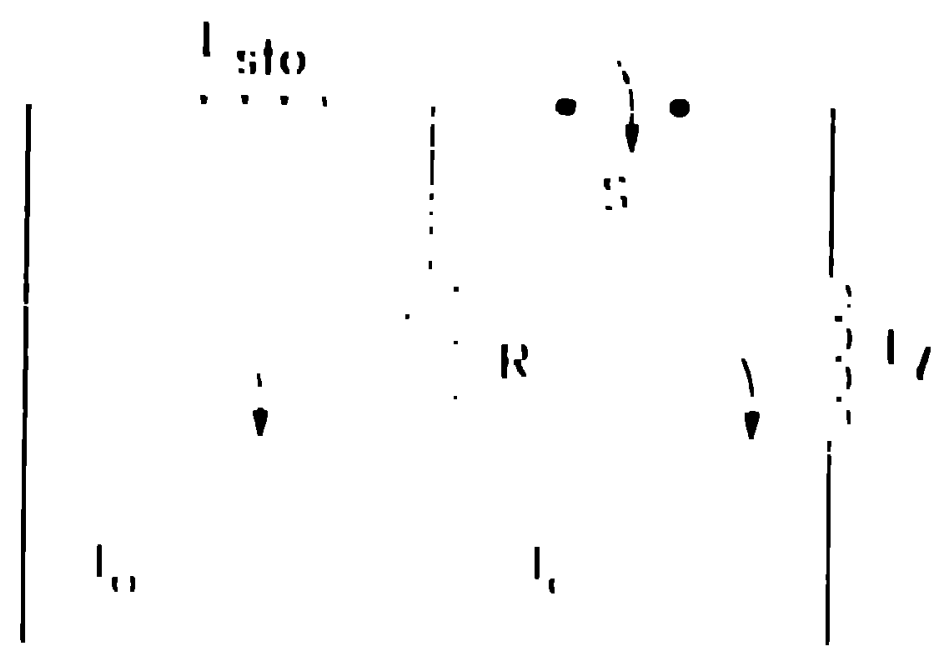




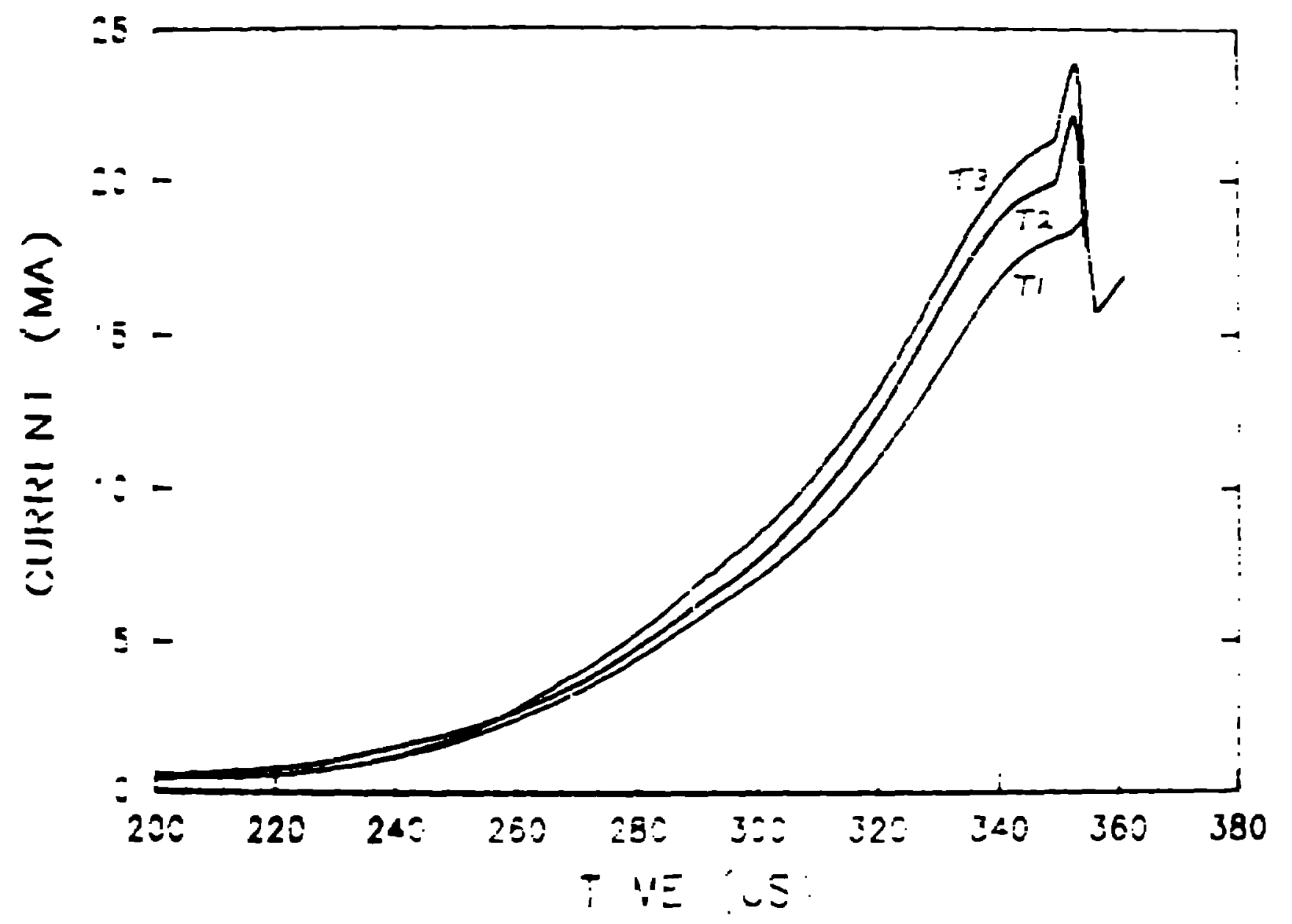

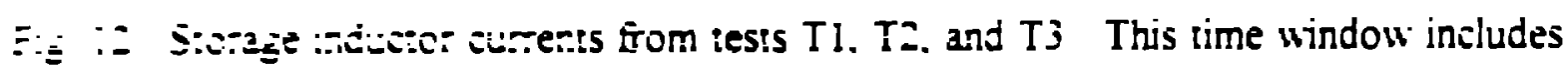

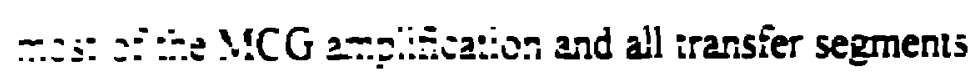




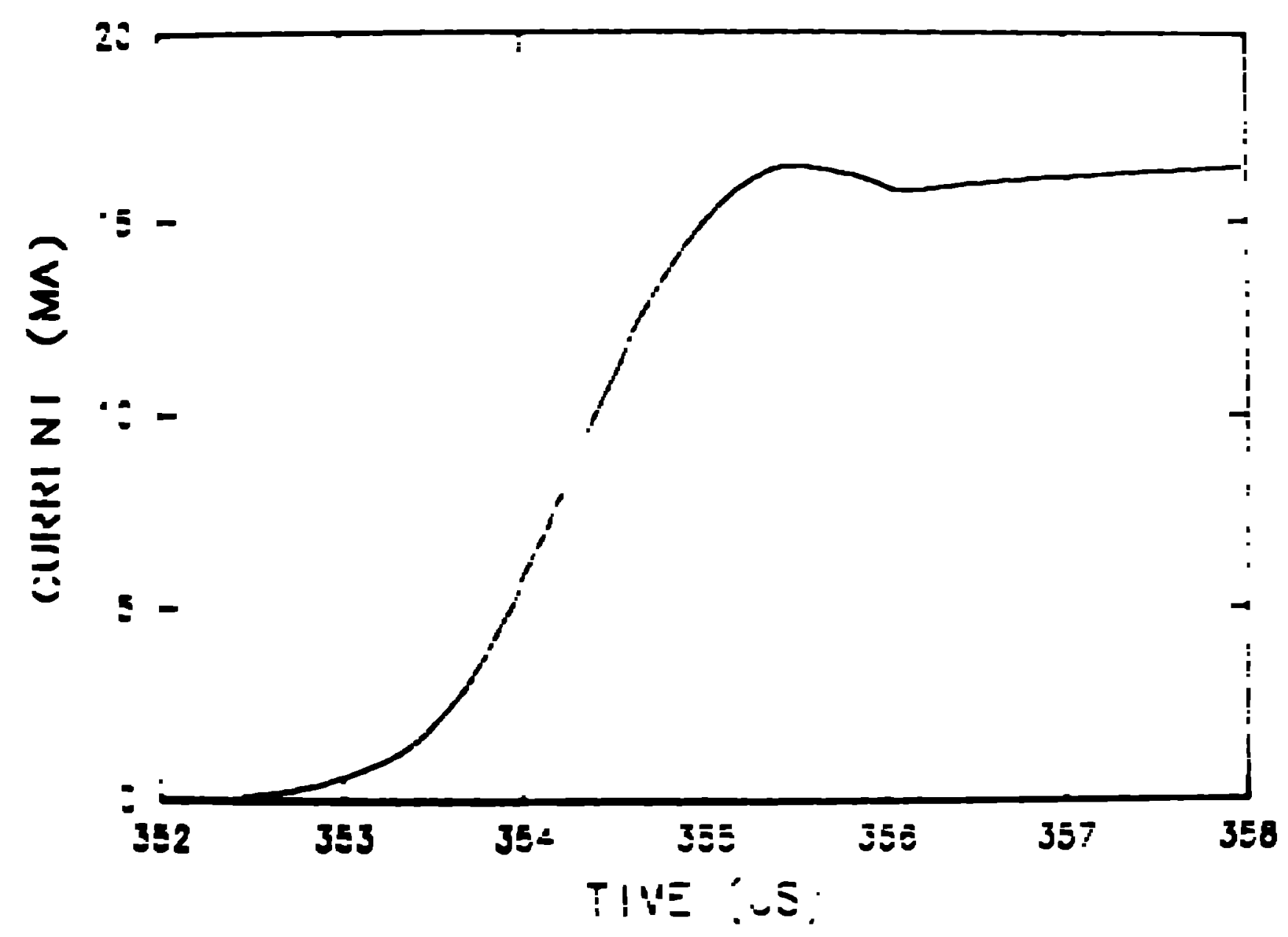

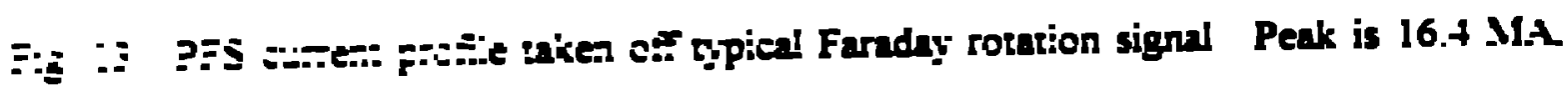

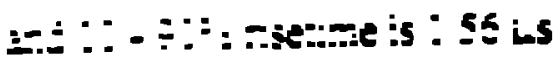




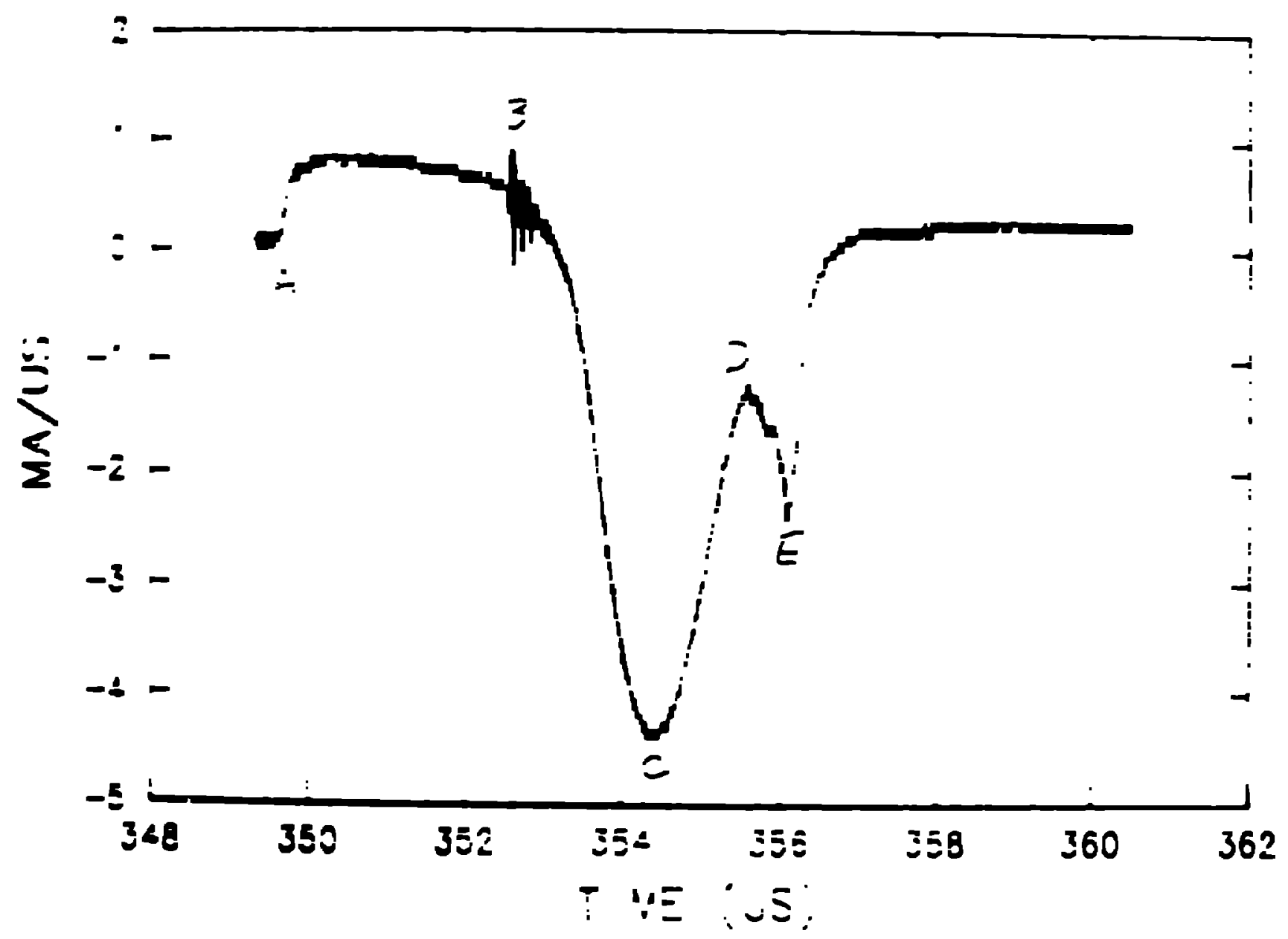

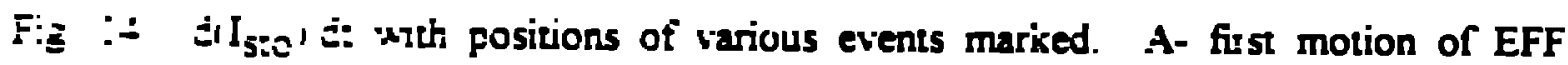
sat_a:z: B- s'esing of detcrator aztuated suitches C- Peak transfer rate to PFS. D-

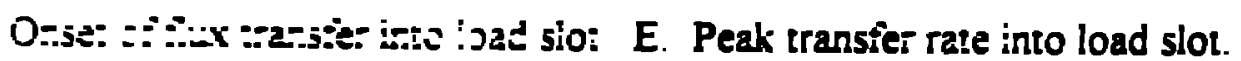




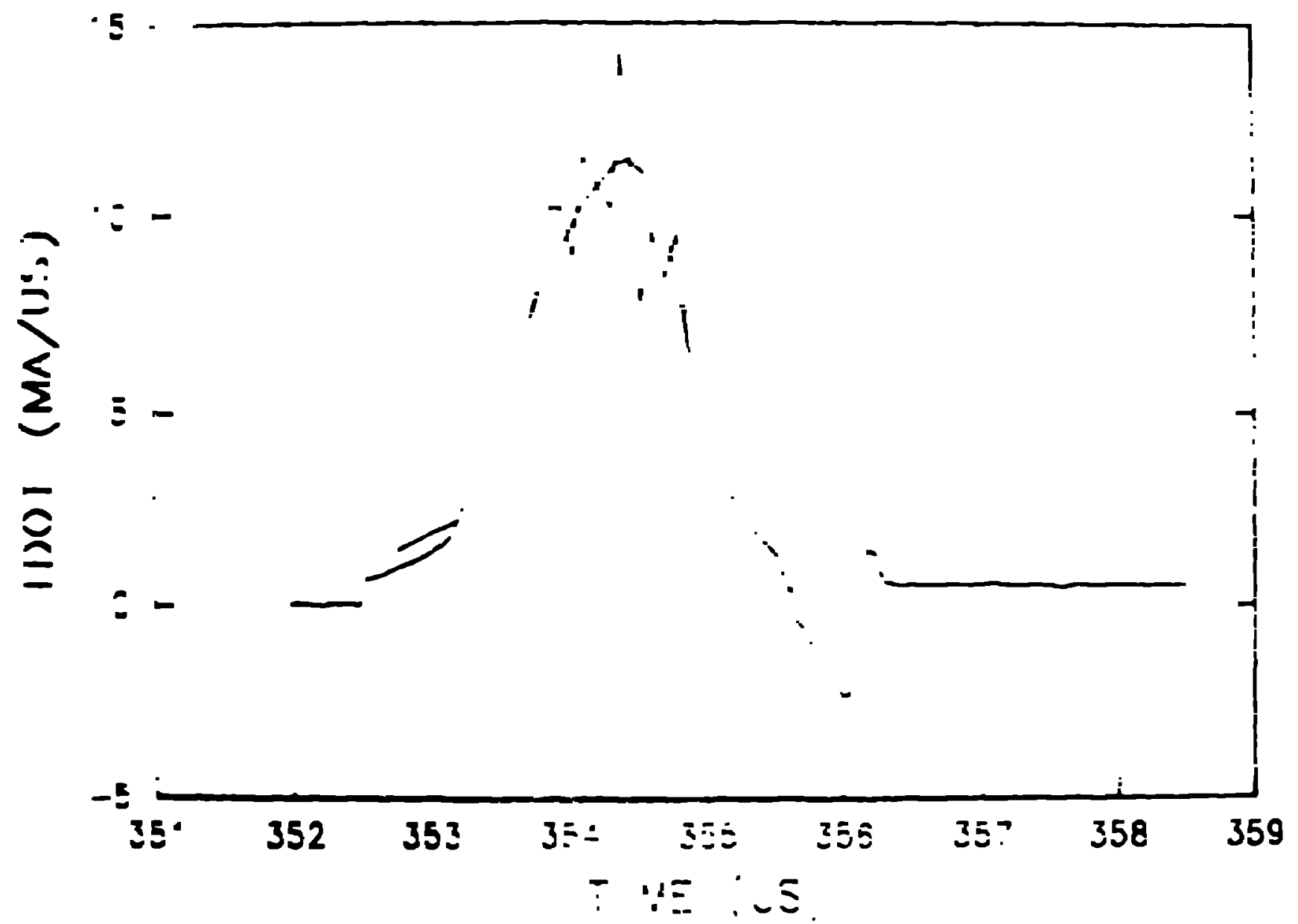

F:s : :s ¿ I IPFS' di combined from Rogowski coil and Faraday rotation sensors. A crude

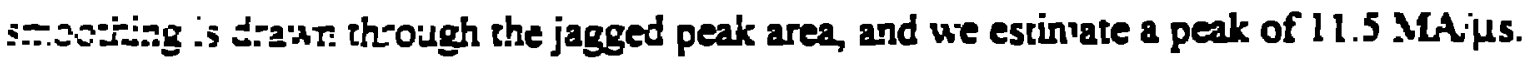




$$
\sum
$$




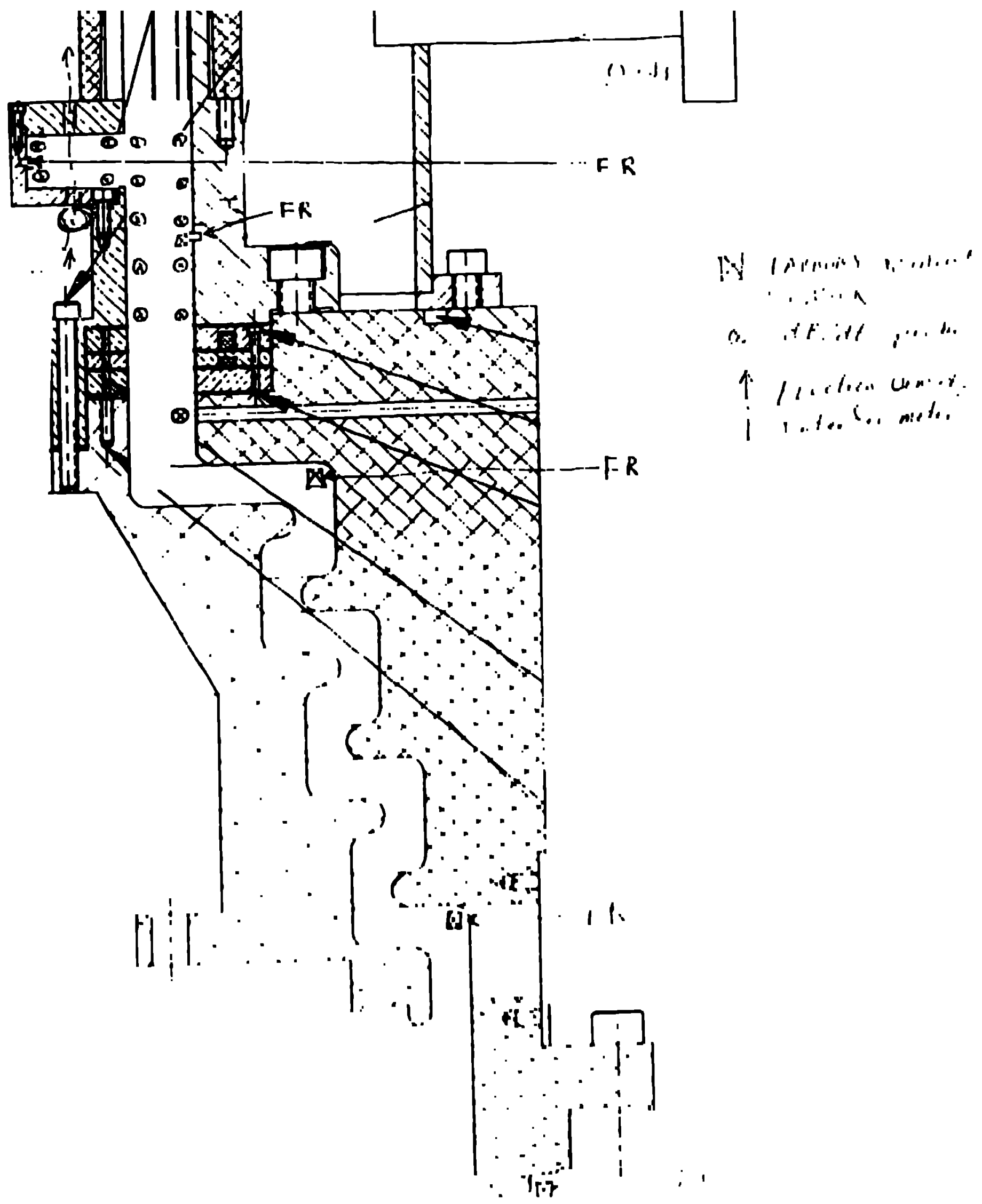

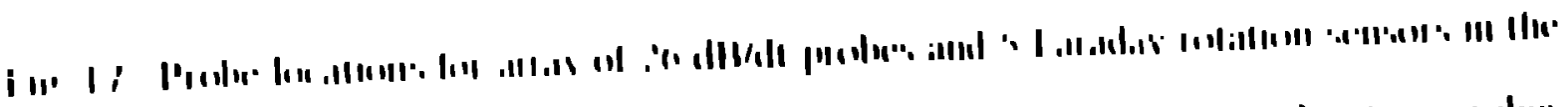

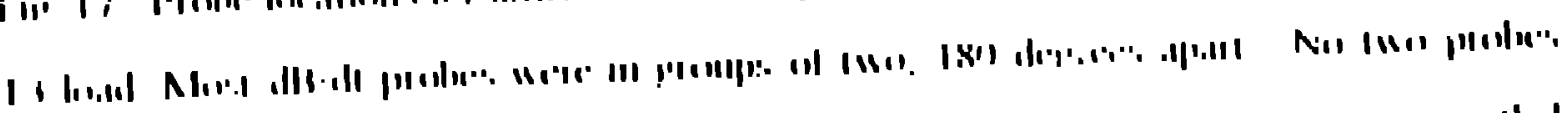

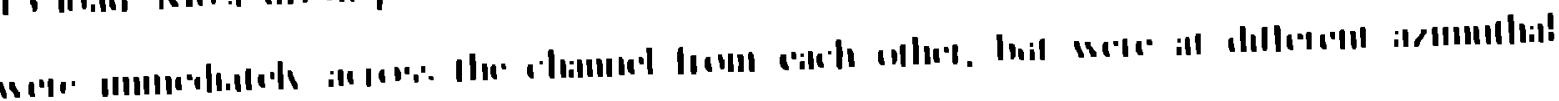




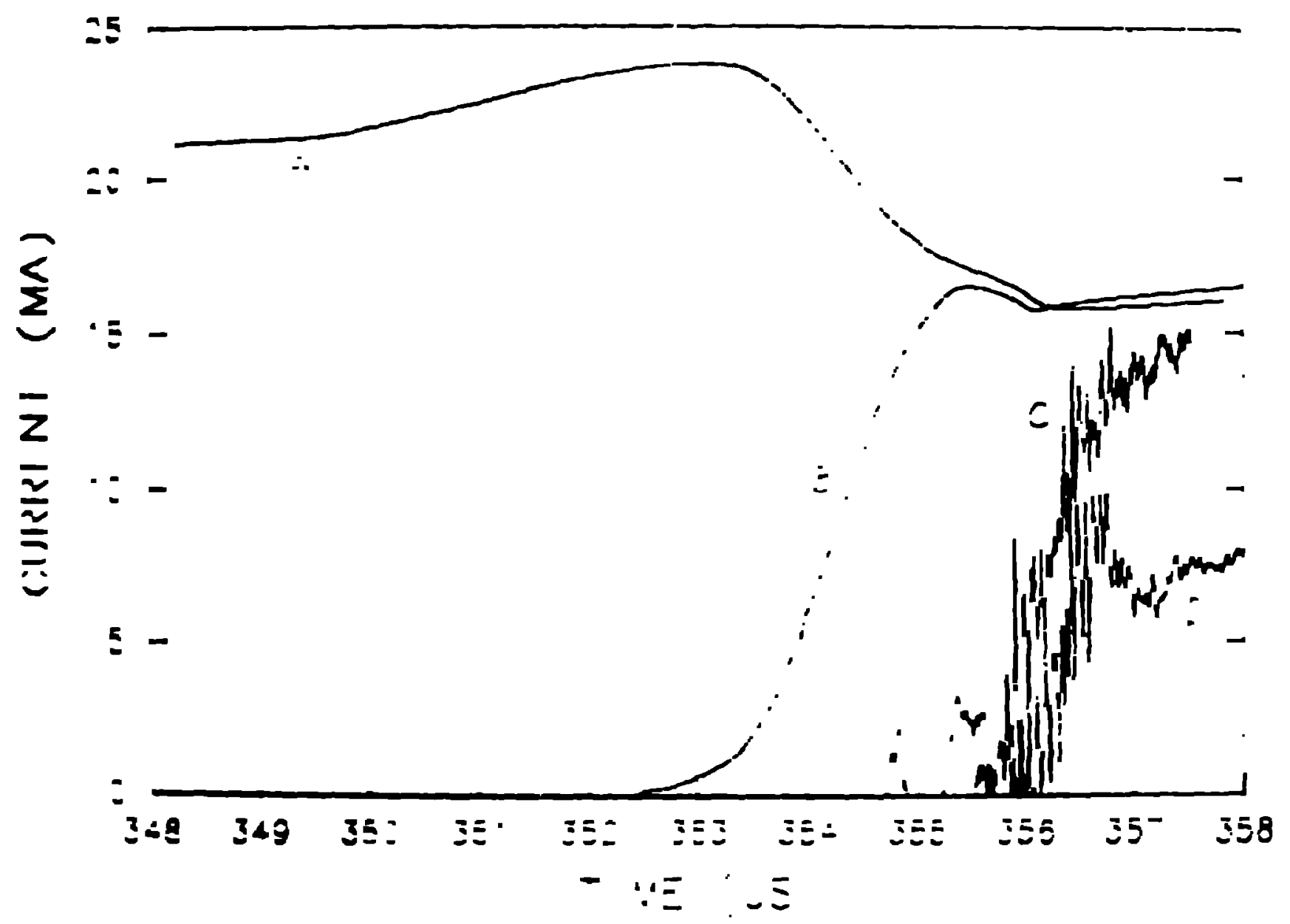

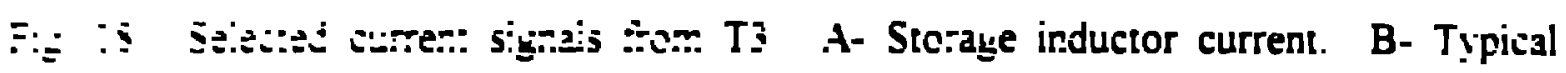

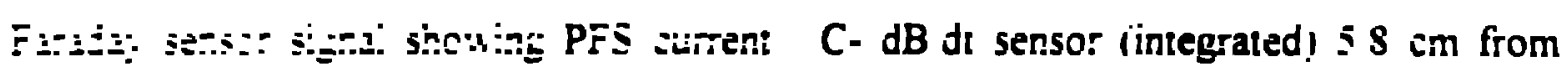

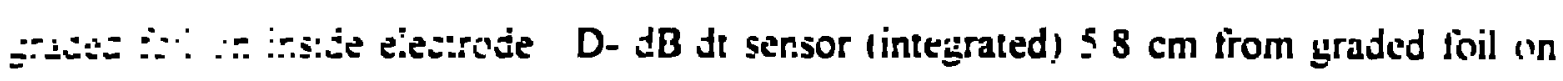
… ... … ... 


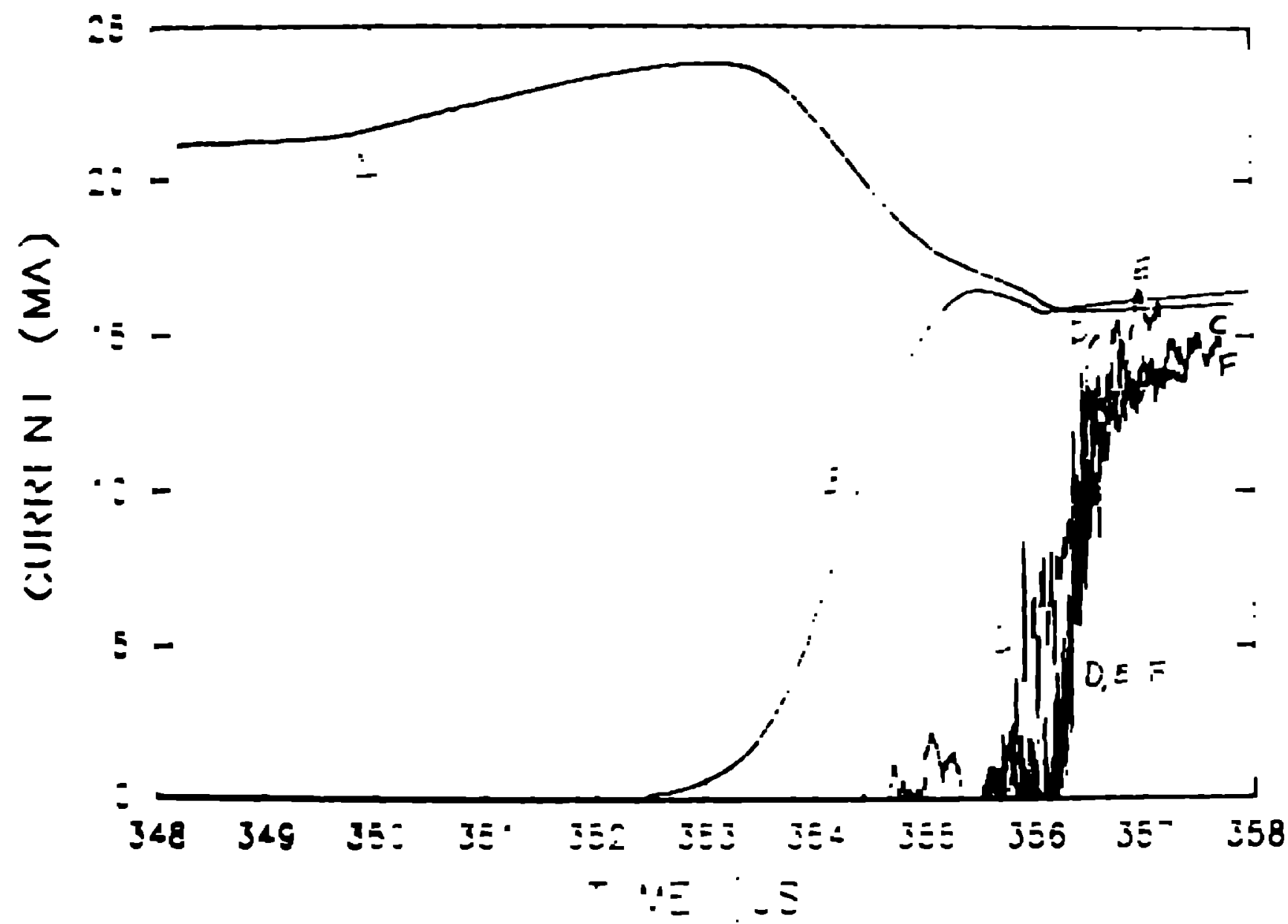

F: :- Se.ev:a zu-ten: signa:s Som T3. A- Storage inductor current B- Typical

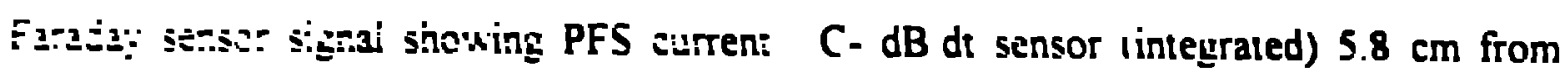

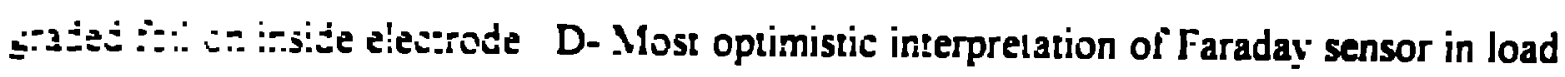
$\therefore:: \leq:: n=E-A B$ di sensor (integrated) recessed inside load slot on upstream side. FiB i: sensor 1 irr:egrated! in bottem of load slor. 

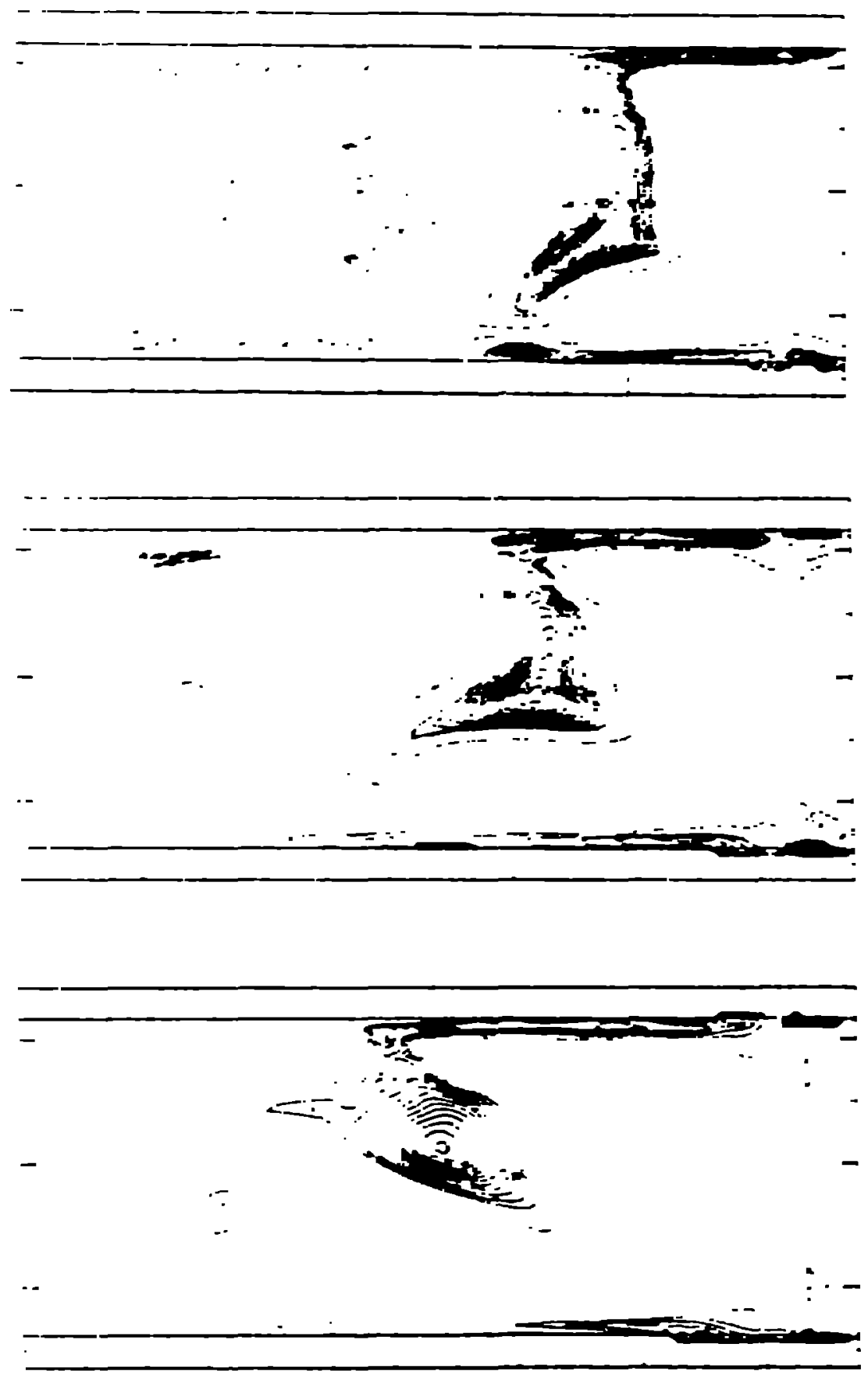

Fig. 20 2D RIIHD calculations of a $1 \mathrm{r}$ gun plissia driven with T3 waveform Frane 1. at $3 j \mu 5$. shows onset of mass-thiuning. Frame 2 at $3.5 \mu \mathrm{s}$, shows that flux has flooded through the gun plasma Frame 3 at $37 \mu \mathrm{s}$. shows that the PFS has opened and remains so 